(C) 2022, The Authors. Published by Elsevier Inc. and Fass Inc. on behalf of the American Dairy Science Association ${ }^{\circledR}$. This is an open access article under the CC BY license (http://creativecommons.org/licenses/by/4.0/).

\title{
Invited review: A comprehensive review of visible and near-infrared spectroscopy for predicting the chemical composition of cheese
}

\author{
Giovanni Bittante, ${ }^{1}$ Nageshvar Patel, ${ }^{1}$ Alessio Cecchinato, ${ }^{1 *}$ and Paolo Berzaghi ${ }^{2}$ \\ ${ }^{1}$ Department of Agronomy, Food, Natural resources, Animals and Environment (DAFNAE) University of Padova (Padua), 35020 Legnaro, Italy \\ ${ }^{2}$ Department of Animal Medicine, Production and Health (MAPS), University of Padova (Padua), 35020 Legnaro, Italy
}

\begin{abstract}
Substantial research has been carried out on rapid, nondestructive, and inexpensive techniques for predicting cheese composition using spectroscopy in the visible and near-infrared radiation range. Moreover, in recent years, new portable and handheld spectrometers have been used to predict chemical composition from spectra captured directly on the cheese surface in dairies, storage facilities, and food plants, removing the need to collect, transport, and process cheese samples. For this review, we selected 71 papers (mainly dealing with prediction of the chemical composition of cheese) and summarized their results, focusing our attention on the major sources of variation in prediction accuracy related to cheese variability, spectrometer and spectra characteristics, and chemometrics techniques. The average coefficient of determination obtained from the validation samples ranged from 86 to $90 \%$ for predicting the moisture, fat, and protein contents of cheese, but was lower for predicting $\mathrm{NaCl}$ content and cheese $\mathrm{pH}$ (79 and $56 \%$, respectively). There was wide variability with respect to all traits in the results of the various studies (standard deviation: 9-30\%). This review draws attention to the need for more robust equations for predicting cheese composition in different situations; the calibration data set should consist of representative cheese samples to avoid bias due to an overly specific field of application and ensure the results are not biased for a particular category of cheese. Different spectrometers have different accuracies, which do not seem to depend on the spectrum extension. Furthermore, specific areas of the spectrum - the visible, infrared-A, or infrared-B range - may yield similar results to broadrange spectra; this is because several signals related to cheese composition are distributed along the spectrum. Small, portable instruments have been shown to be viable alternatives to large bench-top instruments. Last,
\end{abstract}

Received April 21, 2021

Accepted September 26, 2021.

*Corresponding author: alessio.cecchinato@unipd.it chemometrics (spectra pre-treatment and prediction models) play an important role, especially with regard to difficult-to-predict traits. A proper, fully independent, validation strategy is essential to avoid overoptimistic results.

Key words: dairy product, near-infrared, visible-near infrared (Vis-NIR), Fourier transform infrared (FTIR), portable spectrometer

\section{INTRODUCTION}

Cheese is a very important dairy food, and its importance is reflected in the fact that $\sim 30 \%$ of the world's raw milk production is used for cheesemaking (Eurostat, 2020); in some countries, such as Italy, the figure is almost $80 \%$. Moreover, the proportion of milk destined for cheese production is increasing worldwide (USDA-FAS, 2021).

Differences in the characteristics of the raw milk, the cheesemaking procedures, and the length and conditions of ripening affect the chemical composition and, consequently, the physical and rheological traits, nutritional value, sensorial profile, microbiota, and other features of the cheese. The importance of the chemical characteristics of cheese and the variations in them from product to product make analysis of them essential. Conventional "wet chemistry" methods for determining the different chemical components of cheese require cheese samples to be collected and transported to a laboratory, stored, prepared, and processed. Such methods also often involve the use of reagents that generate chemical waste, raising some concern in the society of being potentially toxic to humans and the environment. Although they are accurate and yield precise results, they are very cumbersome, destructive, and time- and resource-consuming (McQueen et al., 1995; Karoui et al., 2006a; Lénárt et al., 2012). The importance of efficient routine analyses of cheese composition to cheese producers, retailers, and consumers has prompted the development of rapid, nondestructive, and inexpensive methods to predict the main components of cheeses such as fat, protein, moisture, and many others. Of 
these, spectrometric methods have proven to be very useful, especially at the industry level (McQueen et al., 1995; Rodriguez-Otero et al., 1995; Karoui and Debaerdemaeker, 2007). As several characteristics of cheese have been shown to also depend on the genetics of dairy animals (Bittante et al., 2013; Bergamaschi et al., 2016; Pegolo et al., 2018; Stocco et al., 2018), there is also interest in predicting cheese traits from milk spectra for application in selective breeding at the dairy population level (Bittante et al., 2014; Cecchinato et al., 2015, 2020).

Over several decades, studies have been carried out on the application of near-infrared (NIR) spectroscopy (NIRS) to predict cheese composition using different approaches, instruments, and chemometric methods, and some useful review articles on these topics have been published in the past. Polesello et al. (1983) summarized the first uses of NIRS to study the optical properties of some dairy products. Additional work was carried out by Giangiacomo and Nzabonimpa (1994) on the development and application of NIR technology to dairy products. Their reviews also cite industrial applications and the main factors affecting measurements. There have been a few other recent reviews, including Panikuttira et al. (2018) and Pu et al. (2020), on the use of nondestructive techniques to evaluate process analytical technology in cheesemaking plants. De Marchi et al. (2018) presented an overview of infrared applications for assessing several characteristics of different dairy products, which included some information on cheese composition, and Lei and Sun (2019) looked at different nondestructive techniques for evaluating the quality attributes of cheese, including NIRS. A collection of performance of validated NIR applications used routinely for quality control of solid, semi-solid, and liquid samples in dairy industry laboratories and by instruments vendors have been published recently by the International Dairy Federation (Niemöller and Holroyd, 2019). Nevertheless, there is a lack of recent reviews focusing specifically on the current literature on NIRS prediction of the chemical composition of cheese and analysis of the influence of the major sources of variation in prediction accuracy. Interest has also been fostered by the appearance on the market of small, inexpensive, handheld instruments that are robust and easy to use, and with which spectra can be obtained directly from the surface of the cheese without the need to collect, transport, and process samples. These instruments can be used in dairy processing plants, ripening cellars, and retail centers without the need for dedicated laboratories.

The intention here is to provide an overview of the progress of research on NIRS for predicting the chemical composition of cheese, placing emphasis on the criti- cal factors that explain prediction effectiveness and the risks of obtaining overoptimistic results.

The review is organized into the following sections: (1) trends in publications on NIR prediction of cheese composition; (2) accuracy of NIRS prediction of the chemical composition of cheese; (3) cheeses analyzed;

(4) spectrometers and spectra; (5) chemometrics; and (6) conclusions.

\section{TRENDS IN PUBLICATIONS ON NIRS PREDICTION OF CHEESE COMPOSITION}

Research on spectral analysis of infrared electromagnetic radiation to predict cheese composition has a history spanning more than 40 yr (Biggs, 1979; Frank and Birth, 1982). At first, few scientific articles per year were published, but their number increased in the period of 2005 to 2010 ( 8 and 12 articles per year) and decreased in later years. At first, the studies almost exclusively used bench-top spectrometers for predicting the fat, protein, and moisture and DM contents of cheeses. Later, predictions were extended to $\mathrm{NaCl}$ content, cheese $\mathrm{pH}$, and other nutrients (Karoui et al., 2006c; González-Martín et al., 2008; Lucas et al., 2008). More recently, the research objectives were broadened to include portable instruments, more detailed chemical profiles, and new chemometric approaches. These topics will be discussed later.

From the $(\sim 200)$ articles on the prediction of cheese characteristics published in indexed journals over the last 4 decades, we selected 71 that dealt with prediction of the chemical composition of cheese, and that reported enough information to allow us to compare their results and draw inferences regarding the effects of several technical features and statistical approaches. These articles were published mainly in highly reputed journals, more than half in the Q1 quartile of the categories "Food Science" and "Agriculture, Dairy and Animal Science" and especially in the Journal of Dairy Science, International Dairy Journal, and Journal of Near-Infrared Spectroscopy (Table 1).

\section{ACCURACY OF NIRS PREDICTION OF THE CHEMICAL COMPOSITION OF CHEESE}

The most important results from the selected articles are summarized in Table 2. As can be seen, a large number of the studies deal with prediction of the moisture (or DM) and fat content of cheese, and a smaller number with prediction of the protein content (about half those dealing with moisture and fat), $\mathrm{NaCl}$ content, and cheese $\mathrm{pH}$ (about a quarter). Few articles deal with prediction of other chemical components of cheese. A summary of the performance of NIRS on a wide range 
Table 1. Bibliometric information ${ }^{1}$ on the first 10 indexed scientific journals ranked according to the number of articles published on the prediction of cheese composition by near-infrared spectroscopy

\begin{tabular}{|c|c|c|c|c|c|c|}
\hline \multicolumn{2}{|c|}{ Source } & \multirow{2}{*}{$\begin{array}{c}\begin{array}{c}\text { No. of } \\
\text { articles }\end{array} \\
15\end{array}$} & \multirow{2}{*}{$\begin{array}{r}\text { Impact } \\
\text { Factor }\end{array}$} & \multirow{2}{*}{$\begin{array}{c}\text { Ranking } \\
5 / 63\end{array}$} & \multirow{2}{*}{$\frac{\text { Quartile }}{\text { Q1 }}$} & \multirow{2}{*}{$\frac{\text { h-index }}{2}$} \\
\hline 1 & Journal of Dairy Science & & & & & \\
\hline 4 & Food Chemistry & 7 & 6.306 & $6 / 139$ & Q1 & 242 \\
\hline 5 & Talanta & 5 & 5.339 & $11 / 86$ & Q1 & 154 \\
\hline 6 & Journal of Food Engineering & 5 & 4.499 & $16 / 139$ & Q1 & 167 \\
\hline 9 & $\begin{array}{l}\text { Guang Pu Xue Yu Guang Pu Fen XI/Spectroscopy } \\
\text { and Spectral Analysis }\end{array}$ & 4 & 0.452 & $42 / 42$ & Q4 & 29 \\
\hline 10 & Food Research International & 3 & 4.972 & $11 / 139$ & Q1 & 149 \\
\hline
\end{tabular}

${ }^{1}$ Bibliometric information came from the ISI Web of Science database accessed in fall 2020 and reporting 2019 evaluations. Where a journal is included in more than one subject category, the quartile and ranking refer to the category with the journal's highest evaluation.

${ }^{2}$ Hirsch index. Although more often used as an author-level metric, the h-index can be used to rank journals. The h-index of the journal is determined as follows: $\mathrm{h}$ papers that have each been cited at least $\mathrm{h}$ times.

of dairy products is reported in a specific bulletin of the International Dairy Federation (Niermöller and Holroyd, 2019), and this was the base of the guidelines for the application of near-infrared spectrometry to milk and milk products (ISO, 2006), recently updated (ISO, 2020). These documents are especially focused on the large laboratories of the milk-recording systems and of the dairy industry.

The articles on cheese prediction summarized in Table 2 are highly varied in their experimental design, the cheeses analyzed, the spectrometers used, and the statistical methods adopted. Therefore, the averages and standard deviations (SD) presented in Table 2 should be treated with caution and considered merely a first approach to the results with an indication of their variability as well as a signal of the need for closer analysis of their many sources of variation.

\section{NIRS Prediction of Cheese Moisture}

The accuracy of moisture prediction obtained from the calibration data sets was on average $90 \%$, but there were large differences between the various studies, as indicated by the SD of $\pm 13 \%$ and the extreme values of $57 \%$ and $99 \%$ (Table 2). The average accuracy obtained from the validation sets (mainly cross-validation) was almost identical to that from the calibration sets, but it should be pointed out that only some of the publications report both accuracy parameters. A summary of the data can be found in Supplemen-

Table 2. Summary of the results reported in 71 publications on prediction of the chemical composition of cheeses using infrared spectrometry in terms of accuracy of calibration $\left(\mathrm{R}_{\mathrm{CAL}}^{2}\right)$, accuracy of validation $\left(\mathrm{R}_{\mathrm{VAL}}^{2}\right)$, and root mean standard error of validation (RMSE $\left.\mathrm{VAL}\right)$

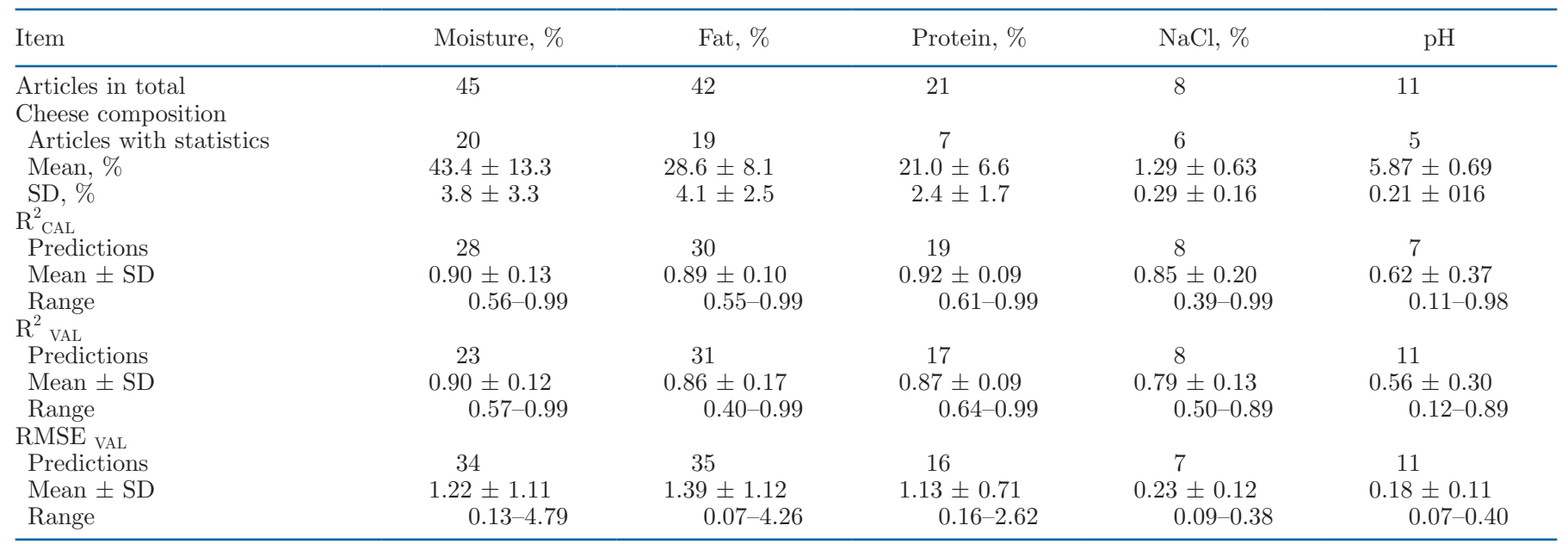


tal Table S1 (https://figshare.com/articles/journal _contribution/Supplementary_Tables_JDS_article _Invited_review_A_comprehensive_review_of_visible _and_near-infrared_spectroscopy_for_predicting _the_chemical_composition_of_cheese/16908787). The root mean squares error of validation $\left(\mathbf{R M S E}_{\mathrm{VAL}}\right)$ in the published studies was on average \pm 1.22 percentage points of moisture (or TS or DM), with very large variability among the articles $(\mathrm{SD}=1.11 \%$, with the extreme values $0.13 \%$ and $4.79 \%$ ).

\section{NIRS Prediction of Cheese Fat}

The average accuracy value of the equations developed for predicting the fat content of cheese (Table 2) was similar to that for moisture content, for both calibration $(89 \%)$ and cross-validation $(86 \%)$. The variability in the results was lower for calibration $( \pm 10 \%)$ than for validation $( \pm 17 \%)$, which shows that fat prediction is more sensitive to the validation strategy used. Details of the accuracy parameters of the fat predictions are given in Supplemental Table S2 (https://figshare.com/articles/journal _contribution/Supplementary_Tables_JDS_article _Invited_review_A_comprehensive_review_of_visible _and_near-infrared_spectroscopy_for_predicting_the _chemical_composition_of_cheese/16908787). The average $\mathrm{RMSE}_{\mathrm{VAL}}$ for fat prediction was similar to that for moisture prediction, and there was also a similar very large variability in this parameter (Table 2 ).

\section{NIRS Prediction of Cheese Protein}

The average accuracies of prediction of the total CP content of cheese $(\mathrm{N} \times 6.38)$ from both the calibration and cross-validation data sets were similar to those for moisture and fat contents (Table 2). The variability in the published estimates was also similar, but only for the calibration data set. It was much lower for the validation set. Therefore, protein prediction seems to be less sensitive to validation strategies than fat prediction. The accuracy parameters reported in the selected scientific literature for the prediction of cheese protein are shown in Supplemental Table S3 (https://figshare.com/articles/journal _contribution/Supplementary_Tables_JDS_article _Invited_review_A_comprehensive_review_of_visible _and_near-infrared_spectroscopy_for_predicting_the _chemical_composition_of_cheese/16908787). The average $\mathrm{RMSE}_{\mathrm{VAL}}$ was also similar to that for moisture and especially to that for fat, but exhibited less variability, probably in relation to lower average content of protein showed by different samples and the more constant composition in milk, compared with moisture and fat (Table 2).

\section{NIRS Prediction of the $\mathrm{NaCl}$ Content and $\mathrm{pH}$ of Cheese}

There are very few studies on the prediction of the $\mathrm{NaCl}$ content and $\mathrm{pH}$ of cheese, and thus the data summarized in Table 2 should be treated with great caution. It is evident that neither $\mathrm{pH}$ nor mineral contents are directly related to some vibrational property of the cheese and that their prediction by NIRS could only be correlative in nature (i.e., based on associations of $\mathrm{pH}$ and mineral contents with other chemical characteristics of cheese. The average accuracies of the prediction of $\mathrm{NaCl}$ from the calibration $(85 \%)$ and validation $(79 \%)$ data sets are slightly lower than those for the predictions of moisture, fat, and protein, whereas the average accuracies of predicting $\mathrm{pH}$ are much lower (62\% and $56 \%$, respectively). In contrast, the variability in the accuracy parameters for $\mathrm{NaCl}$ content and for $\mathrm{pH}$ are much greater than for other nutrients. The accuracy parameters reported in individual studies for the prediction of $\mathrm{NaCl}$ content are shown in Supplemental Table S4, and for the prediction of $\mathrm{pH}$ in Supplemental Table S5 (https://figshare.com/articles/journal _contribution/Supplementary_Tables_JDS_article _Invited_review_A_comprehensive_review_of_visible _and_near-infrared_spectroscopy_for_predicting _the_chemical_composition_of_cheese/16908787). The $\mathrm{RMSE}_{\mathrm{VAL}}$ of these 2 traits are obviously much lower than those for moisture, fat and protein, given the very low variability in their content in cheese.

\section{Usefulness of NIRS Predictions}

The ratio between the $\mathrm{SD}$ and the $\mathrm{RMSE}_{\mathrm{VAL}}$ of a given nutrient is known as the ratio percentage deviation (RPD) and is a parameter often used for evaluating the practical value of predictions and for comparing different traits. As the RPD is the ratio between the total variability of the nutrient in cheese and the variability not accounted by the NIR spectra, conceptually, it is not much different from the meaning of an $\mathrm{R}^{2}$. The differences are that $R^{2}$ is a ratio of variances and not of $\mathrm{SD}$, that it quantifies the variance explained by NIR spectra instead of residual variance, and that numerator and denominator of the ratio are exchanged. This means that RPD could be directly derived from $\mathrm{R}^{2}$ $\left(R P D=1 / \sqrt{ }\left(1-R^{2}\right)\right)$. According to Viscarra Rossel et al. (2007), an RPD less than 1.0 indicates a very poor model $\left(\mathrm{R}^{2}<0.00\right)$, RPD between 1.0 and 1.4 indicates a poor model $\left(\mathrm{R}^{2}: 0.00\right.$ to $\left.<0.49\right)$, RPD between 1.4 to 
and 1.8 indicates a fair model $\left(\mathrm{R}^{2}: 0.49\right.$ to $\left.<0.69\right), \mathrm{RPD}$ between 1.8 and indicates 2.0 a good model $\left(\mathrm{R}^{2}: 0.69\right.$ to $<0.75)$, RPD between 2.0 and 2.5 indicates a very good model $\left(\mathrm{R}^{2}: 0.75\right.$ to $\left.<0.84\right)$, and RPD greater than 2.5 indicates an excellent model $\left(\mathrm{R}^{2}:>0.84\right)$. This parameter is sometimes reported in the published studies or can be calculated from their statistical parameters, but is often not available. Moreover, being a ratio value, averaging it is questionable. The ratio between the mean "within study" SD and the mean $\mathrm{RMSE}_{\mathrm{VAL}}$ listed in Table 2 could stand for an average RPD value, although it should, of course, be borne in mind that the nominator and denominator were calculated from different studies and reflect differences in the materials and procedures used. Nevertheless, the ratio was 3.1 for the prediction of moisture (excellent), 2.9 for fat (excellent), 2.1 for protein (very good), 1.3 for $\mathrm{NaCl}$ (poor), and 1.2 for cheese $\mathrm{pH}$ (poor). This value represents a rough estimate of the mean RPD of the different studies. Using the ratio of the "across studies" SD instead of the "within studies" SD as the nominator could give an idea of the upper limit of the predictions that could be obtained in future research from large data sets of many types of cheeses or from meta-analyses. The values thus obtained were as follows: 10.9 for moisture, 5.8 for fat, 5.8 for protein, 2.7 for $\mathrm{NaCl}$, and 3.8 for $\mathrm{pH}$, theoretically corresponding to $\mathrm{R}^{2}$ of $0.99,0.97,0.97,0.86$, and 0.93 , respectively. Therefore, for all these traits, excellent predictions appear to be obtainable under proper conditions and with proper methods. As a result, there is room for much improvement in the accuracies of the predictions of cheese composition. This also draws attention to the need for greater understanding of the critical factors affecting the accuracy of NIRS predictions of cheese quality traits, particularly those factors related to (1) the types of cheese analyzed, (2) the spectrometer and spectra characteristics, and (3) the chemometrics (mathematical pretreatment of spectra, calibration models and procedures, and validation strategies).

\section{THE CHEESES ANALYZED}

\section{Cheese Types and Numbers}

The cheeses studied were mainly produced from cow milk, and only in a few cases from milk from small ruminants or mixed milks (González-Martín et al., 2008, 2011; Stocco et al., 2019). The large majority of the studies were carried out on a single type of cheese as follows: commercial cheeses, local cheeses, or experimentally-produced cheeses. Details of the types and compositions of the cheeses analyzed in the studies can be found in Supplemen- tal Table S6 (https://figshare.com/articles/journal _contribution/Supplementary_Tables_JDS_article _Invited_review_A_comprehensive_review_of_visible _and_near-infrared_spectroscopy_for_predicting_the _chemical_composition_of_cheese/16908787). Some studies compared predictions obtained from cheeses at different stages of the cheesemaking process (McKenna, 2001), different moisture levels (da Costa Filho and Volery, 2005), or produced in different seasons (González-Martín et al., 2011). Few studies compared specific predictions obtained from different types of cheese (McKenna, 2001), or they made broad predictions not from a specific type of cheese but rather from a combination of a few types (Frank and Birth, 1982; Rodriguez-Otero et al., 1995; Lucas et al., 2008; Lénárt, et al., 2012) or many types of cheese (Stocco et al., 2019).

The number of cheese samples used for the reference analyses and for collecting the spectra varies greatly across different studies. The average was $147 \pm 184$ (SD) samples. The distribution of sample numbers is far from normal. The very large number of samples in one study on many categories of cheese (between 196 and 1,021 samples from 37 cheese categories; Stocco et al., 2019) inflated both the average and the SD. Excluding this study, the average number of samples is $120 \pm 108$. It is worth noting that in about a third of the studies, including some of the recent ones, a very small number of samples $(<60)$ were analyzed. This number appears to be too low to take into account the complexity and heterogeneity of the cheese matrix. According to the International Dairy Federation (Niermöller and Holroyd, 2019), the number of samples of dairy products needed for obtaining a NIR calibration is much larger, and also depends on the chemometric approach used because "a PLS model might need a few hundred and an ANN model, a few thousand samples to become very robust and comprehensive" (see the Calibration Procedures section).

\section{Cheese Sampling and Processing}

In the large majority of cases (i.e., those using laboratory bench-top spectrometers), cheese samples needed to be collected, transported to the laboratory, and processed before the spectra were collected. In almost half the studies (Table 3), the spectra were taken from the intact surface of freshly-cut cheese blocks. In the others, the cheese samples were grated (hard and semihard cheeses), sliced (semi-hard cheeses), or ground (soft and semi-hard cheeses) before spectra collection.

The revised guidelines of the International Dairy Federation on applications of NIRS for the analysis of milk and milk products (Niermöller and Holroyd, 2019) 
Bittante et al.: INVITED REVIEW: NEAR-INFRARED SPECTROSCOPY PREDICTION OF CHEESE COMPOSITION

1822

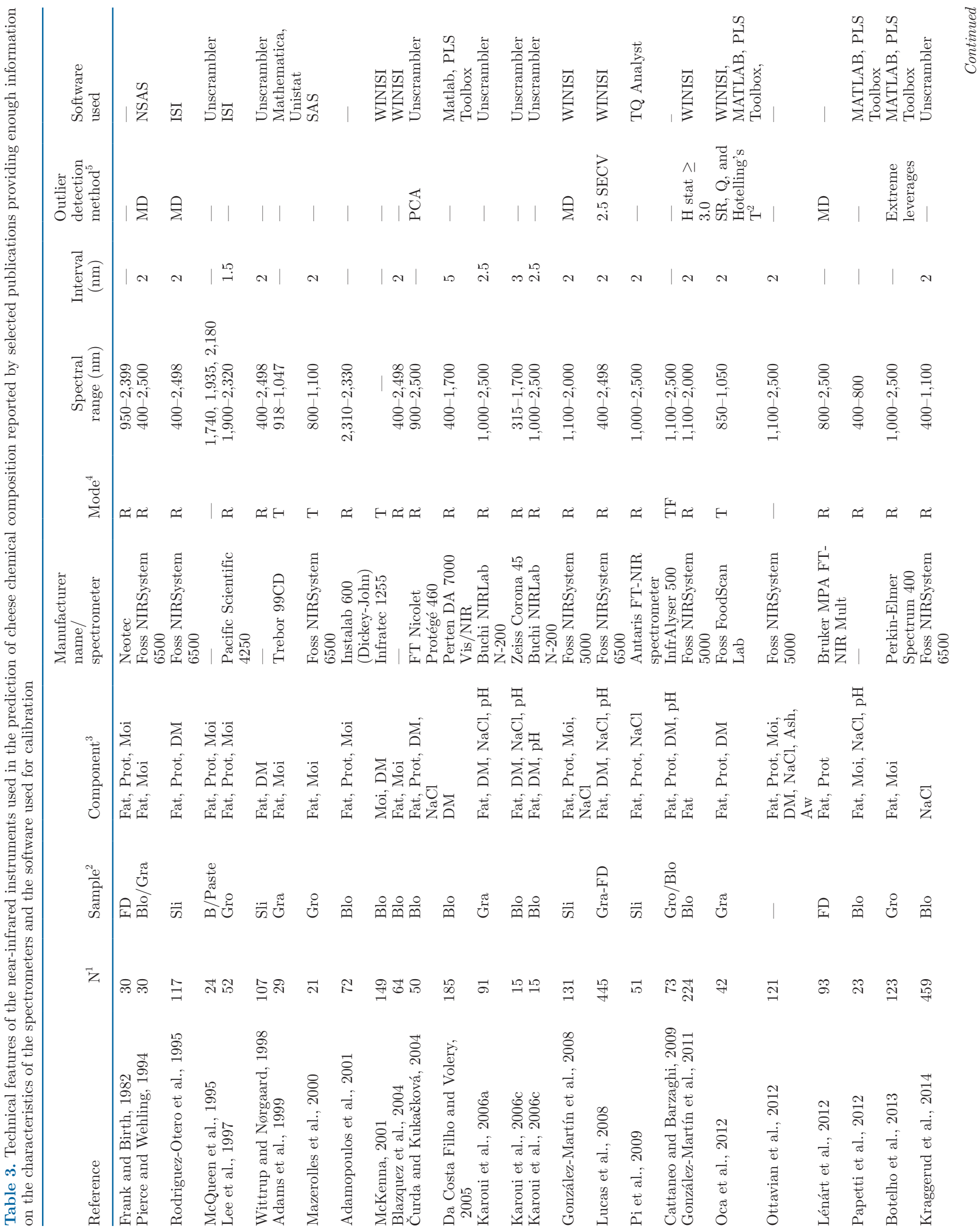

Journal of Dairy Science Vol. 105 No. 3, 2022 


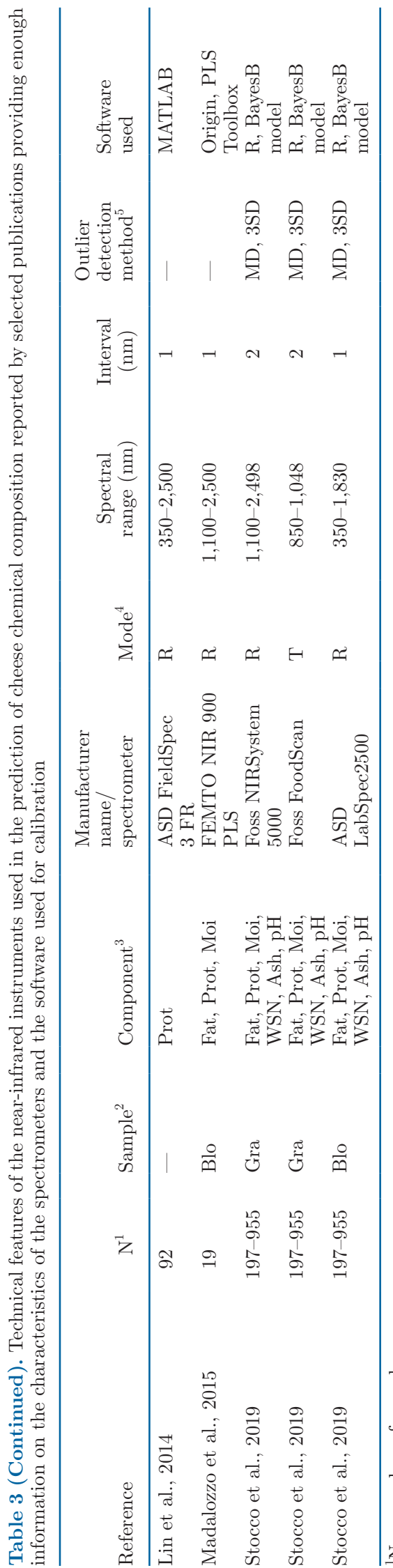

report that, "For solid or semi-solid samples which are not homogenous, a sample preparation step is required. These samples need to be ground or mixed to obtain a homogeneous test sample for analysis. For samples with a varied fat distribution and possible suspended ingredients, it is important to have a sample preparation step which ensures homogeneity of the sample that will be measured, e.g., efficient homogenization." However, some scientific articles studied the effect of sample preparation with different results. Cattaneo and Barzaghi (2009) compared the results obtained from NIR spectra collected from the surface of a block and from grated samples of a hard cheese and found neither procedure to be systematically better than the other for predicting the moisture, fat, and protein content, and pH (Figure 1). However, Wiedemair et al. (2019) recently obtained better predictions using ground cheese samples. It is possible that the comparison was affected by the characteristics of the cheese paste (e.g., holes, crystalline structure), with better results obtained by grinding the more heterogeneous cheeses. Moreover, grating could also increase matrix heterogeneity because of the different size of cheese particles, the variable level of compression, and then the distribution of air within the sample.

In a few cases, the cheese samples were freeze-dried and ground before spectra collection (Frank and Birth, 1982; Lucas et al., 2008; Lénárt et al., 2012). In a direct comparison of predictions obtained from fresh and freeze-dried samples (Lucas et al., 2008), the best results were generally obtained from fresh cheeses (Figure 2 ); therefore, freeze-drying does not seem to be advis-

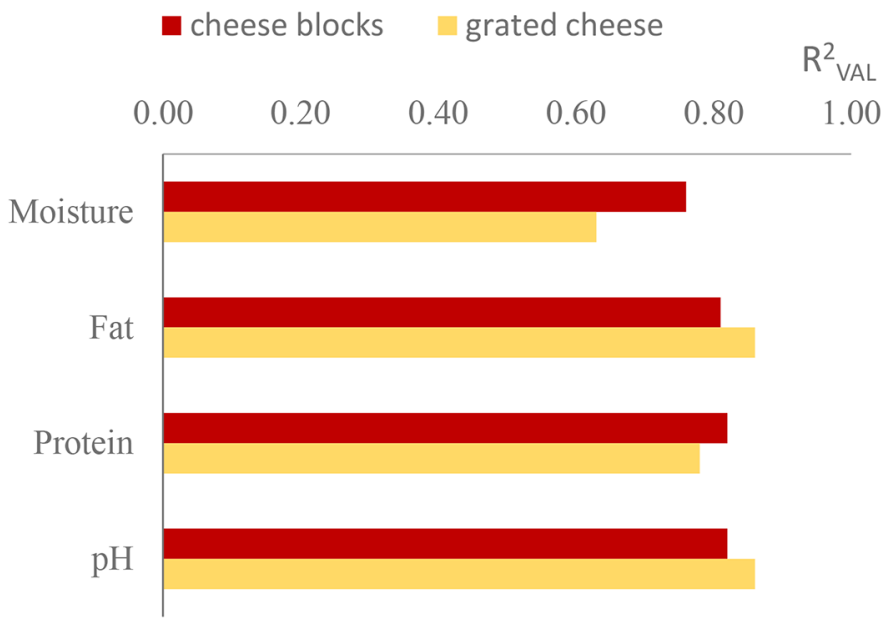

Figure 1. Comparison of accuracies of calibrations obtained from cheese blocks or grated cheese samples for predicting cheese moisture, fat, and protein content percentages and $\mathrm{pH}$ (based on data presented in Cattaneo and Barzaghi, 2009; 73 frozen and thawed samples of Idiazabal cheese of varying ripening ages; near-infrared spectrometer $1,111-2,500 \mathrm{~nm}) \cdot \mathrm{R}_{\mathrm{VAL}}^{2}=$ accuracy of validation 
able beyond the advantage of allowing the samples to be preserved for longer before analysis.

Furthermore, it should be considered that the choice of processing cheese samples depends on the type of instruments adopted. The large bench-top infrared spectrometers, often having internal rotating automatic samplers, require grating and homogenizing pretreatments. Of course, when portable spectrometers were used, cheese sampling was not required (other than for carrying out the reference analyses using gold-standard methods) as the spectra could be taken directly from the freshly cut surface of the cheese (Lin et al., 2014; Stocco et al., 2019).

\section{Reference Chemical Compositions of the Cheeses Sampled}

Less than half of the selected studies reported the chemical compositions of the cheeses in terms of the averages and SD for, at least, the chemical components being predicted. The available data are given in Supplemental Table S6 and summarized in Table 2. It should be pointed out that there are very large differences between studies, not only in the average contents of a given nutrient in the cheese samples analyzed, but also in their "within study" variability. This variability depends on several sources whose relative importance can affect the calibration and improve or worsen the accuracy of NIRS predictions.

Knowing the sources of variation in the content of a given chemical component in cheese (reference values) is fundamental for understanding the possibilities and limits of NIRS predictions. Stocco et al. (2019) quantified the sources of variation in the main nutrients in cheese from a large data set of many different types of cheese. Their results are summarized in Figure 3. As it can be seen, cheese category [individual cheese types where they have European Union Protected Designation of Origin (PDO), or groups of cheeses with similar characteristics and cheesemaking procedures where they are non-PDO] is the most important source of variation in the content of every nutrient in cheese (across-category variability). This is expected because cheese type reflects almost all the differences in the species producing the milk, the pretreatment of the milk, the cheesemaking procedures, the size and shape of the cheese, and the length and conditions of ripening. The variability among different cheeses (wheels or blocks) within a cheese type (within-category variability) is the second most important source of variation in moisture, ash, lipid and water-soluble nitrogen (WSN) contents. However, in the case of protein content, the second source of variation was in different samples taken from the same individual

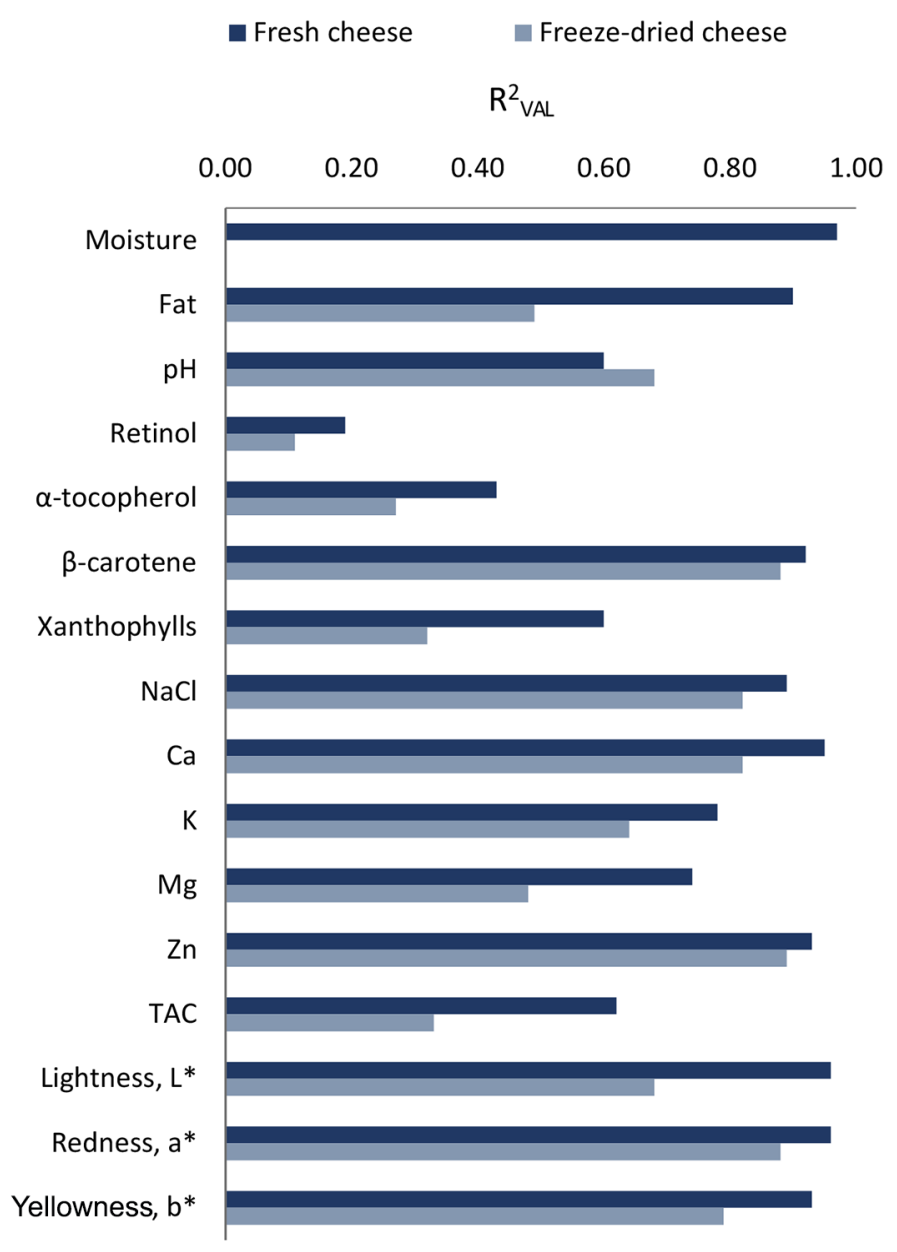

Figure 2. Comparison of accuracies of validations $\left(\mathrm{R}_{\mathrm{VAL}}^{2}\right)$ obtained from fresh cheese or freeze-dried samples for predicting many chemical characteristics of cheese [based on data presented in Lucas et al., 2008; 357 samples for calibration, 83 for validation from Abondance, Tomme de Savoie, Cantal-type and Rocamadour goat cheese; visible-near infrared (Vis-NIR) bench-top spectrometer 400-2,498 nm]. TAC = total antioxidant capacity.

cheese (within-cheese variability). This is also an important source of variation in the other cheese nutrients and underscores the heterogeneity of cheese, the great importance of cheese sampling, and the need to collect the spectra from the same position on the cheese as for the reference analyses. Last, the variability in different replicate analyses of an individual sample (within-sample variability) is more a reflection of the influence of the analytical repeatability of the reference method adopted (analytical error) than a characteristic of the cheese sample. Unlike moisture, ash, protein, and WSN, lipids exhibit greater variability among replicates of the same sample than among different samples of the same cheese.

Reference analysis is crucial because it is the basis for developing the calibration models for NIR spec- 


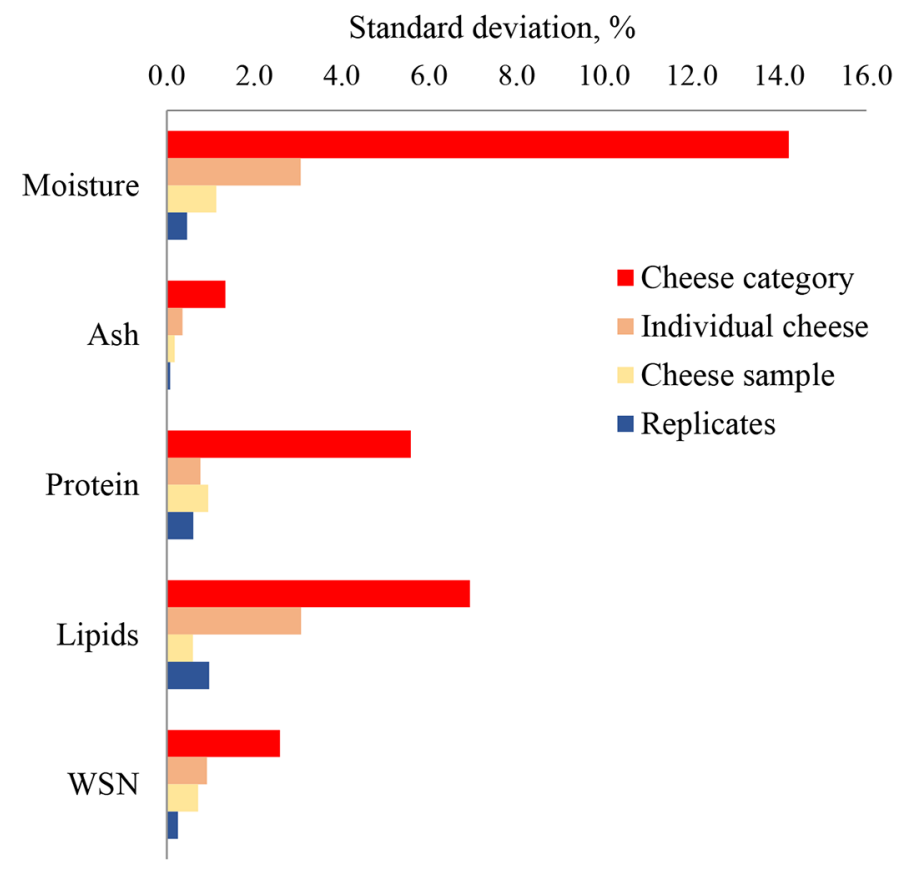

Figure 3. Main sources of variation in the chemical composition of cheese analyzed by gold-standard methods (based on data presented in Stocco et al., 2019). Cheese category refers to individual types of cheese where they have European Union Protected Designation of Origin (PDO), and to groups of cheeses with similar characteristics and cheesemaking procedures where non-PDO; individual cheese refers to single wheels or blocks within a given cheese category; cheese sample refers to different samples taken from the same wheel or block; replicates refers to the different replicates of wet analyses carried out on the same cheese sample. WSN = water-soluble nitrogen (ripening index).

troscopy through the development of regression models between the NIR spectra and the results obtained from laboratory methods. The accuracy of NIRS predictions depends on the repeatability of the reference methods. Clearly, prediction accuracy could theoretically reach the upper limit of $100 \%$, but only if the reference values are the "true" values of the analyzed samples (i.e., if the repeatability and reproducibility of the reference analyses are 100\%). As this is not the case for the chemical composition of a heterogeneous material such as cheese, and as the expected upper limit of NIRS predictions cannot be greater than the repeatability of the reference analyses, the expected maximum coefficients of determination can be calculated (Williams et al., 2017) by knowing the SD and the standard error of the laboratory method (SEL) as $\left[\left(\mathrm{SD}^{2}-\mathrm{SEL}^{2}\right) / \mathrm{SD}^{2}\right]$. It is clear that both calibration and validation cannot have coefficients of determination of $100 \%$ because the error of the NIRS predictions combines the errors of both the reference analyses and the NIR system.
Moisture. The moisture content of the reference samples was generally assessed through oven drying. We found the average value across studies to be $43.4 \%$, accompanied by large differences among the studies (SD: $\pm 13.3 \%$ ), ranging from about $15 \%$ (Frank and Birth, 1982) to $80 \%$ (Madalozzo et al., 2015). The within-study variability was much lower than the between-studies variability (average SD: $\pm 3.8 \%$ ).

Fat. The Gerber procedure was generally used for the reference analysis of lipid content. The average fat content of the cheeses analyzed in 19 studies, excluding freeze-dried samples, was $28.6 \%$, although it varied (Table 2) from $10.6 \%$ in ricotta (Madalozzo et al., 2015) to 41 to $45 \%$ in Spanish cheeses made from mixed cow, ewe, and goat milk (González-Martín et al., 2011). The variety of cheeses analyzed in the different studies was signaled by the large SD of their averages $( \pm 8.1 \%)$. On the other hand, the variability in the fat content of individual samples analyzed in each study was much lower; the average SD within studies was $\pm 4.1 \%$, with large differences across studies (SD of SD: $\pm 2.5 \%$ ). This within-study variability, important for the accuracy of the prediction equations, was sometimes lower than $1 \%$ (Pierce and Wehling, 1994; Adamopoulos et al., 2001; $\mathrm{Pi}$ et al., 2009), and in other cases greater than $5 \%$ (Karoui et al., 2006b; González-Martín et al., 2008; Madalozzo et al., 2015; Stocco et al., 2019).

Protein. The Kjeldahl procedure (total cheese N multiplied generally by 6.38) was used for the reference analysis of protein. The average protein content across the different studies was $21.0 \%$ with high variability (SD: $\pm 6.6 \%$ ); the minimum was $12.4 \%$ in ricotta (Madalozzo et al., 2015), and the maximum was $31.7 \%$ in Colby, Parmesan, Romano, and Gruyere cheeses (Frank and Birth, 1982). The within-study variability for protein was much lower than for fat (average within-study SD: $\pm 2.4 \%$ ), with only 1 study using cheeses from a wide range of categories and with an SD exceeding $5 \%$ (Stocco et al., 2019).

$\mathrm{NaCl}$ and $\boldsymbol{p H}$. The averages and SD of the NaCL content and $\mathrm{pH}$ of cheese are reported in Table 2 , but it should be borne in mind that very few studies included this information.

\section{Effects of Cheese Variability on the Prediction of Chemical Composition}

Where different types of cheese are relatively similar in terms of origin and manufacturing procedures but have different moisture contents, the relative error of prediction of TS (moisture) was found to be lower for those with a high content of total solids than those 
with a low content (Figure 4). Moreover, when specific calibrations are developed separately for each type of cheese the predictions seem to be less accurate than when one broad calibration is developed using samples of all the cheese types of interest (da Costa Filho and Volery, 2005). In the case of the study by da Costa Filho and Volery, all the cheeses were produced in the same plant using a similar procedure, and the common "broad" calibration yielded not only a higher accuracy of validation $\left(\mathbf{R}^{2}\right.$ VAL; which was expected), but also a smaller RMSE $E_{\mathrm{VAL}}$ (which was not expected). When variability is increased by using cheeses of different origins and compositions, a higher $\mathrm{R}_{\mathrm{VAL}}^{2}$ is often also accompanied by a higher $\mathrm{RMSE}_{\mathrm{VAL}}$. This means that the ability of a prediction equation cannot be evaluated on the basis of only one of these fitting parameters, but should instead be evaluated on both. It is also evident that a "broad" calibration is less precise, but possibly more affordable as it can be used with types of cheese that were not included in its development, whereas a more specific calibration may yield biased results if used on samples different from those employed for its development.

However, the use of very broad calibrations does not eliminate the risk of biased results for certain types of cheese, especially for nutrients based more on correla-

\section{Specific calibration Common calibration}

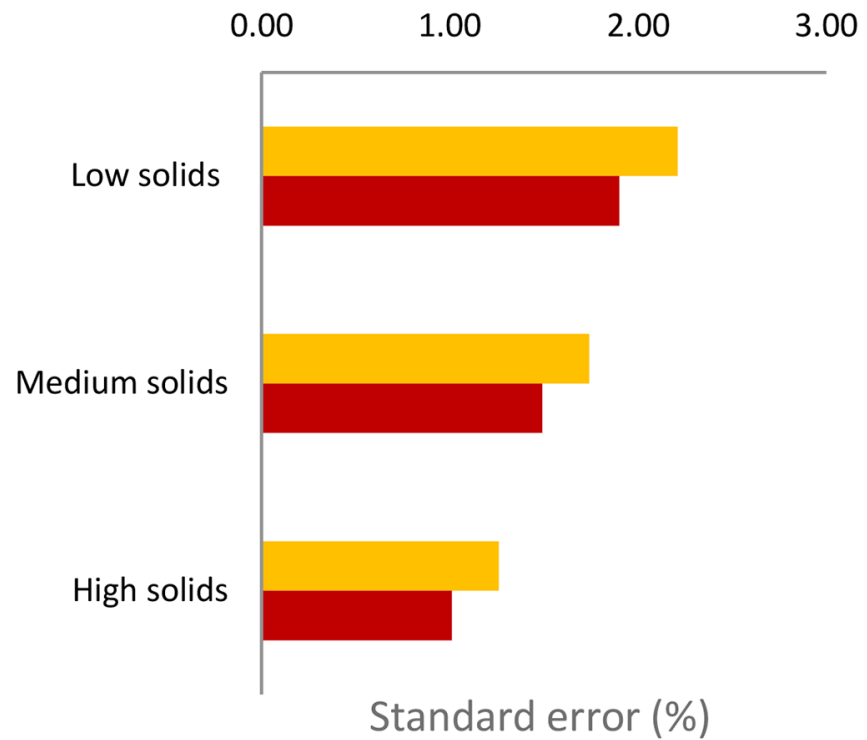

Figure 4. Relative standard error of prediction of the total solids (moisture) content of fresh cheeses (in \%), of 3 types (low, medium, or high content of total solids) obtained using a specific calibration for each type of cheese, or using a common calibration including all the types of cheese (based on data presented in da Costa Filho and Volery, 2005; 185 cheese samples; visible-near infrared spectroscopy $400-1,700 \mathrm{~nm}$ ). tions with other cheese characteristics than with their vibrational patterns and for heterogeneous or differently processed cheese types. Stocco et al. (2019) used a very broad calibration developed from 37 different cheese categories and found an incidence of significantly biased categories (systematic over- or underestimation) ranging from $11 \%$ for moisture to $16 \%$ for protein content predictions (Figure 5), which meant that 84 to $89 \%$ of cheese categories were predicted without bias. The categories most frequently affected by prediction biases were goat cheeses (both rennet and sour coagulation processes), very fresh cheeses, and cheeses with nondairy ingredients added (e.g., pepper or chili) or matured in wine, beer, or vinegar (Stocco et al., 2019). These categories seem to require specific calibrations.

\section{SPECTROMETERS AND SPECTRA}

\section{Spectrometers Used for Predicting Cheese Composition}

A classic NIR spectrometer generally consists of a light source, a beam splitter system (wavelength selector), a sample detector, an optical detector, and a data processing system. The choice of NIR spectrometer depends on its intended use, which is related to the type of specimen and the nature of the results sought. The NIR radiation sources are quartz-tungsten-halogen lamps. All the instruments are available with different types of wavelength-isolating technologies; most of those used in cheese analysis use a monochromatic array, but some use a diode array, Fourier transform

Incidence of biased cheese categories, \%

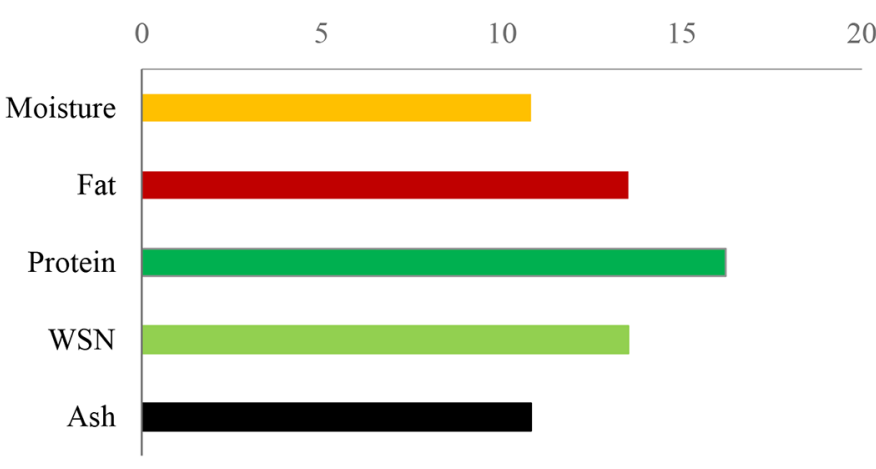

Figure 5. Percentage incidences of categories of cheese in which there is statistically significant bias in the predictions of their chemical compositions obtained from "broad" equations developed using cheeses belonging to all 37 different categories (based on data presented in Stocco et al., 2019). Cheese category refers to individual types of cheese where they have European Union Protected Designation of Origin (PDO), and to groups of cheeses with similar characteristics and cheesemaking procedures where non-PDO. WSN $=$ water-soluble nitrogen (ripening index). 
(FT)-NIR, or filters. (Abbas and Baeten, 2018). Only about half of the selected articles on the prediction of cheese composition provided comprehensive information on their instruments, and these are summarized in Table 3. As can be seen, there were a wide variety of instruments from many manufacturers, although about one-third were made by 1 company. The large majority of the spectrometers were laboratory bench-top instruments working in reflectance mode; however, spectra were collected in transmittance mode or with small, portable instruments in some studies.

\section{Cheese Spectrum in the Range of Visible Light and Infrared Radiation}

The amplitude of the spectrum used differs greatly from spectrometer to spectrometer, and also from study to study as some researchers select only a part of the instrument's spectral range. Moreover, some of the studies reviewed used different spectrum intervals to predict different chemical components (Wittrup and Nørgaard, 1998). Single-channel detectors use lead salt semiconductors, such as lead sulfide (PbS, 1,100-2,500 $\mathrm{nm}$ ), indium gallium arsenide (InGaAs, 800-1,700 nm or extended range up to $2,500 \mathrm{~nm}$ ), and silicon detectors (400-1,100 nm). Multichannel detectors use diode arrays or charge-coupled devices (Abbas and Baeten, 2018). In about one-third of the studies, the visible portion of the electromagnetic spectrum (wavelengths 380 to $740 \mathrm{~nm}$ ) was also included, and not just the near-infrared portion (Table 3). A few studies also included a small portion of UV radiation (wavelengths $<380 \mathrm{~nm}$ ) together with the visible region. According to the CIE (2004), the NIR range is often divided in the following 2 sections: the "infrared A" (IR-A) or NIR (narrow sense) portion of the spectrum (i.e., the interval 740-1,400 nm), and the "infrared B" (IR-B) or short-wavelength infrared region, 1,400 to 2,500 nm. A small number of studies used the IR-A portion alone or combined with the visible portions. The large majority of studies also included part or all of the IR-B portion. It is worth noting that only a couple of the earlier studies used only 2 to 3 individual wavelengths in the IR-B portion of the spectrum (McQueen et al., 1995; Adamopoulos et al., 2001). Figure 6 summarizes the absorbance spectra of about 1,000 cheeses belonging to many categories (e.g., different dairy animal species, milk pretreatments, cheesemaking procedures, ripening duration and conditions) obtained using the following 3 very different spectrometers: a portable visible-NIR (Vis-NIR) reflectance instrument, a laboratory narrow IR-A transmittance instrument, and a laboratory wide-spectrum (IR-A and IR-B) reflectance instrument (Stocco et al., 2019). The figure shows that the spectra obtained in transmittance mode are different but parallel to those obtained in reflectance mode. A few studies also used mid-infrared (MWIR) spectra to predict the chemical composition of cheese (Martín-del-Campo et al., 2007; Margolies and Barbano, 2018); these instruments often require a quite different sample preparation.

The absorbance measurements were recorded at intervals varying from every 1 to every $5 \mathrm{~nm}$ (Table 3 ). This means that the number of absorbance values for each spectrum of each cheese sample varies from only 125 to 150 with the narrow IR-A spectrometers to 1,500 to 2,300 with the more recent portable Vis-NIR spectrometers (Lin et al., 2014; Stocco et al., 2019).

\section{Variability in Cheese Spectra}

We are not aware of any scientific study analyzing and quantifying the main sources of variation in the absorbance of cheese at each individual wavelength of the spectrum. Therefore, specific studies are needed to improve interpretation of the results reported in the different scientific articles. In the case of FTIR spectra of milk, many studies found very large differences in the variability in the absorbances of some fractions of the spectrum. In particular, the transition area between the short-wave infrared (IR-B) and MWIR regions (wavelength 2,730-3,270 $\mathrm{nm}$ ) and another area of the MWIR region (wavelength 5,890 to $6,310 \mathrm{~nm}$ ) exhibited very high variability caused by the absorbance of electromagnetic radiation by water molecules (Bittante and Cecchinato, 2013). This and other studies found that phenotypic variance in absorbance is due in part to the cow's genetic background, and there are large differences in the heritability estimates across different wavelengths.

The sources of variation in the visible and NIR fractions of the electromagnetic spectrum were studied in detail in another food of animal origin (beef meat). With regard to the NIR portion of the meat spectrum, Savoia et al. (2020) observed that the main causes of variation in the IR-A and IR-B segments had very different structures. Neither the batch of carcasses nor the samples taken within each carcass greatly affected the absorbance of any wavelength. In contrast, individual carcass had a very large effect on the absorbance of the wavelengths of the IR-A portion, and a very small effect on the IR-B portion, whereas the opposite pattern was observed for the residual variation among replicates on the same sample. As a result, the repeatability of the absorbance of each individual wavelength was much larger for the IR-A (70-80\%) than for the IR-B (10-40\%) wavelengths. In the case of the visible radiations, the situation was much more variable and 


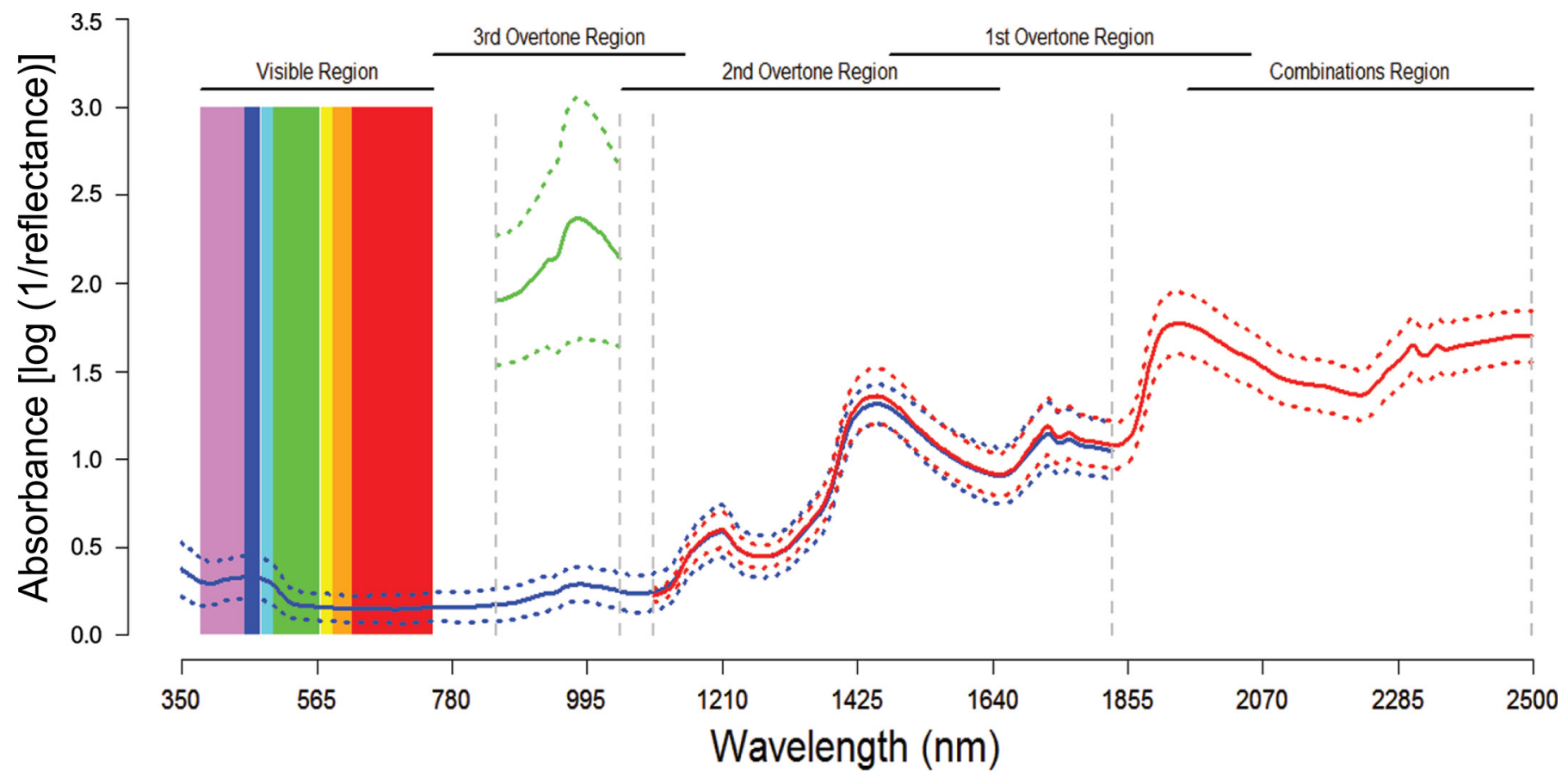

Figure 6. Comparison of the absorbance spectra of cheeses (988-1,021 cheeses of 37 different categories) yielded by a portable reflectance visible-near infrared (Vis-NIR) instrument (blue lines), by a laboratory narrow IR-A transmittance instrument (green lines), and by a laboratory wide-spectrum (IR-A and IR-B) reflectance instrument (red lines). Solid lines represent the average absorbance, and dashed lines represent the average plus and minus the standard deviation (reprinted from Stocco et al., 2019). IR-A = near-infrared, short-wave infrared, 740 to 1,400 nm; IR-B = long-wavelength infrared, 1,100-2,500 $\mathrm{nm}$.

the repeatability of absorbance ranged from about $70 \%$ of some wavelengths in the cyan and green color range to only $20 \%$ of some violet radiations (Savoia et al., 2020). In the case of cheese, the authors are unaware of any specific study on the sources of variation in the absorbance of different wavelengths of the spectrum, but these differences could affect the comparison of spectrometers based on their spectrum extensions. This situation is improved by the ability of some spectrometers to automatically yield "average" spectra from several replicates taken from the same position (thus reducing the residual variability), and by researchers taking spectra from different positions on the same sample and averaging them before using them for calibration (thus reducing the sampling variability).

\section{Relationships Between Individual Wavelength Absorbances and the Nutrient Contents of Cheese}

Several studies, summarized in Table 4, have attempted to assign specific wavelengths to predictions of the fat, protein, and moisture contents of cheese. The results vary across the different studies to a much greater extent than when FTIR wavelengths are used to predict milk composition (Bittante and Cecchinato,
2013). As Table 4 shows, both the IR-A and IR-B sections are closely involved in the prediction of fat, protein, and water contents. This shows that a relatively narrow NIR area is also potentially useful for predicting cheese composition. There is not enough information yet to be able to assign individual wavelengths in the visible radiation region to predictions of the chemical components of cheese. Further research in this area is needed.

\section{Comparison of Different Spectrometers and Spectrum Intervals}

Very little information is available regarding the usefulness of specific areas of the visible and NIR regions of the cheese spectrum for predicting the chemical composition of cheese. As different spectrometers often have different spectrum extensions, it is clear that direct comparison of different instruments leaves open whether any differences between them are due to the portion of spectrum covered or to other technical features of the instruments. Stocco et al. (2019) tried to disentangle the role of spectrum extension from that of other technical features in a comparison of 3 very different spectrometers as follows: a portable 
Table 4. Wavelength band assignment in relation to the chemical composition of cheeses

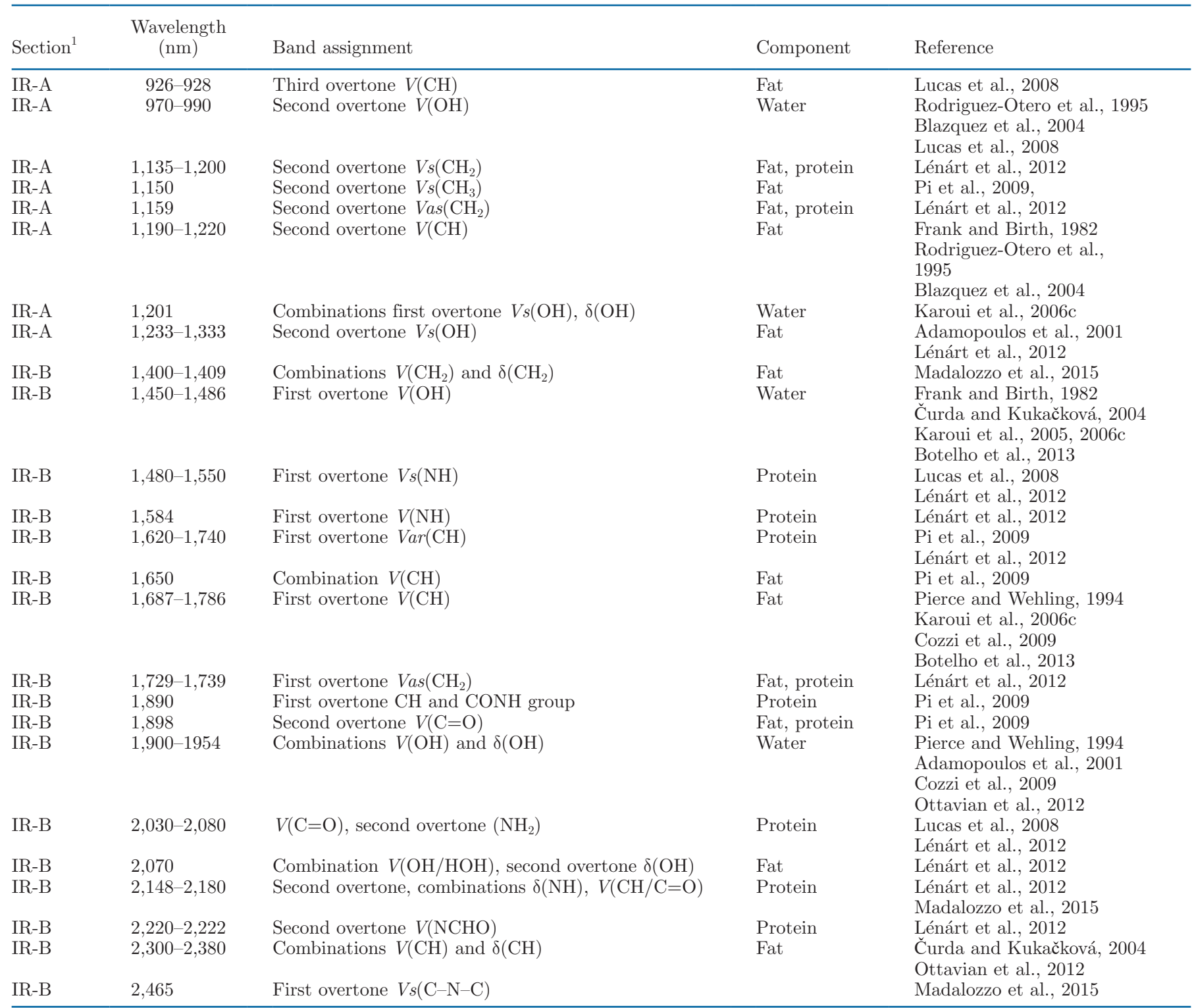

${ }^{1} \mathrm{IR}-\mathrm{A}=$ near-infrared, short-wave infrared, 740 to $1,400 \mathrm{~nm}$; IR-B = long wavelength infrared, 1,100 to 2,500 $\mathrm{nm}$.

spectrometer (VisNIRS-R) covering a wide portion of the spectrum that included a small portion of the UV region, all the visible and all the IR-A regions, and only part of the IR-B region (350-1,830), working in reflectance mode; a laboratory bench-top NIR spectrometer (NIRS-T) covering a narrow part of the IR-A region (850-1,050 nm), working in transmittance mode; and a NIR spectrometer (NIRS-R) covering part of the IR-A and all of the IR-B regions (1,100-2,498 nm), working in reflectance mode. The spectra from the 3 instruments are depicted in Figure 6. In the case of the predictions of moisture, fat, and protein contents, all spectrometers performed in the range of $\mathrm{R}_{\mathrm{VAL}}^{2} 0.64$ to 0.96 with a clear ranking of VisNIRS-R > NIRS-R $>$ NIRS-T (Figure 7). In the case of those chemical traits that are more difficult to predict and more correlative in nature (ash, WSN, and $\mathrm{pH})$, the results were less satisfactory $\left(\mathrm{R}_{\mathrm{VAL}}^{2}: 0.12-0.68\right)$, and the ranking was VisNIRS-R $\approx$ NIRS-R $\geq$ NIRS-T. However, the authors also compared the spectrometers using common spectrum intervals instead of their whole spectrum intervals. When they compared the whole spectrum of the NIRS-T (850-1,050 nm) with the corresponding fraction of the VisNIRS-R spectrum, the authors found that the latter instrument still performed better than the former, as was the case when their entire spectrum 
intervals were compared (Figure 7). Similarly, NIRS-R performed less well than VisNIRS-R, both when their common spectrum intervals $(1,100-1,830 \mathrm{~nm})$ and their entire spectrum intervals were compared. This means that, in predicting cheese chemical composition, the differences between the instruments tested have little to do with the spectrum extension, but more with other technical features (i.e., light source, probe design and opening, detector characteristics such as signal-to-noise ratio, linearity, and dynamic range).

These analyses also allowed us to compare the effectiveness of specific fractions of the spectrum compared with the entire spectrum covered by a given instrument. In the case of the VisNIRS-R, Figure 7 shows that using the UV-Vis fraction $(350-850 \mathrm{~nm})$ alone was as effective as using the whole spectrum for predicting difficult-to-predict traits (ash, WSN, and $\mathrm{pH}$ ), was almost as effective for predicting protein and moisture, and was much less effective in predicting the fat content of cheese. The 2 NIR fractions of the VisNIRS-R spectrometer (850-1,050 and 1,100-1,830 nm) were about as effective as the whole spectrum for all traits. In the case of NIRS-R, the 2 fractions $(1,100-1,830$ and $1,830-2,498 \mathrm{~nm}$ ) were also about as effective individually as in combination for predicting all traits (Figure 7). Similar results were obtained by Wiedemair et al. (2019), who compared a narrow interval (740-1,070 $\mathrm{nm})$ with a much broader one $(800-2,500 \mathrm{~nm})$. These results show that none of the chemical components of cheese tested is related to a specific fraction of the visible or NIR spectrum, and that different signals in different parts of the spectrum can be used alone or in combination for prediction. In the case of portable instruments and especially of pocket-sized NIRS, the information is scarce and research on the effect of possible reduction or expansion of wavelength range and of sampling technics to improve representativity of scans will be useful.

\section{Portable and Handheld Micro-NIR Spectrometers}

Many sample detectors or chambers are restricted to use in laboratory settings. Portable devices, however, have broadened the field of application of visible and NIR spectroscopy and brought changes to the dairy sector. In a rapidly changing environment, where industry is seeking greater control over quality and consumers want rapid and reliable results, these powerful, handheld instruments have many advantages (e.g., small size, low cost, robustness, simplicity of analysis, sample user interface, portability, and ergonomic design) that make them a viable option for nondestructive, online, or in situ analysis, thus fulfilling an industry need (Teix- eira dos Santos et al., 2013). These developments have enabled NIR spectroscopy technology to be applied in a wider range of situations. For example, the fiber optic cable in portable instruments is now being used to evaluate cheese quality (Adams et al., 1999; NúñezSánchez et al., 1999; Lin et al., 2014). More recently, other new, pocket-sized NIR instruments have been developed and used to analyze the fat, moisture, and protein contents of cheese (Eskildsen et al., 2019; Ma et al., 2019; Wiedemair et al., 2019). Portable instruments now have similar accuracy parameters to traditional laboratory bench-top spectrometers (Fernández-Pierna et al., 2010; Eskildsen et al., 2019; Wiedemair et al., 2019; Stocco et al., 2019).

\section{CHEMOMETRICS}

The third important source of variability in prediction results after the type and number of samples analyzed, and the instrument type and spectrum extension, is data treatment. The mathematical pretreatment of spectral data, the chemometric approach (particularly the statistical model applied), and the validation strategy are all important for the final results. Several studies have analyzed the effects of one of these statistical steps, but very few have analyzed them all together, and there is a clear need to do so.

\section{Sample Selection and Identification of Outliers}

The first step, related to the validation strategy, is the selection of samples (according to both their goldstandard composition and spectra) in relation to their variability. Two contrasting approaches can be taken as follows: the first is the elimination of outliers (extreme samples) to obtain a more homogeneous collection of cheese samples; the second is the elimination of "average" samples (with respect to both composition and spectra) because they probably do not contribute as much to the estimation of the prediction equation coefficients as the extreme ones do. Outliers are often detected simply by using the SD to evaluate the distribution of the samples in terms of their chemical composition (for example, $\pm 3 \mathrm{SD}$ ), or using the residual SD if the distribution is based on heterogeneous groups of samples (i.e., different categories).

Several methods are used to detect outlier spectra (Table 3). The most widespread is Mahalanobis distance (De Maesschalck et al., 2000), which can also be used to discard the "average" spectra (i.e., those closer to the center of the distribution) to identify the samples to be analyzed using gold-standard methods. In a few cases, other strategies were used to identify 


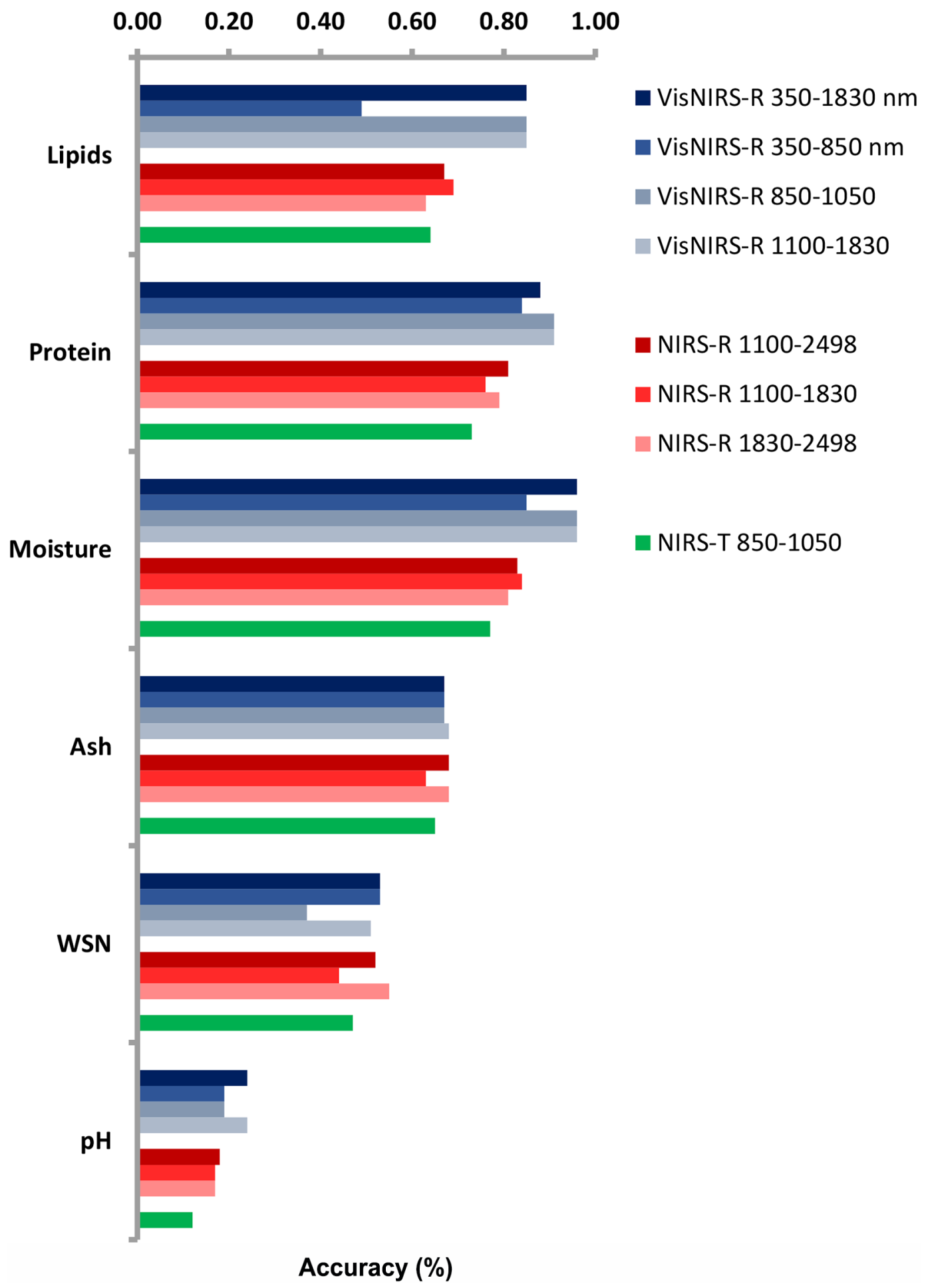

Figure 7. Effects of different infrared spectrometers and spectral intervals on the accuracy of cross-validation of chemical predictions of 197 cheese samples belonging to 37 different cheese categories (based on data presented in Stocco et al., 2019). WSN = water-soluble nitrogen; VisNIRS-R = portable visible-near-infrared spectrometer in reflectance mode; NIRS-R = laboratory near-infrared spectrometer in reflectance mode; NIRS-T = laboratory near-infrared spectrometer in transmittance mode. 
outlier samples (Čurda and Kukačková, 2004; GonzálezMartín et al., 2011; Oca et al., 2012; Botelho et al., 2013), and some studies identified the outlier samples a posteriori and eliminated on the basis of the residuals from the calibration equation, which forced a reduction in the RMSE $E_{\mathrm{VAL}}$ and an increase in the $\mathrm{R}_{\mathrm{VAL}}^{2}$ (Lucas et al., 2008). In any case, the effects of different sample selection strategies and outlier detection procedures on the effectiveness of the prediction equations tested by genuinely independent validation procedures is insufficiently understood.

\section{Mathematical Pretreatments}

Visible and NIR spectra comprise chemical and analyte information together with random and systematic sources of variation unrelated to the chemical composition of the cheese. These sources of variations mask the variances of interest in the cheese (e.g., those related to fat, protein, and DM) and hence reduce the effectiveness of the calibration model (Sena et al., 2018). The aim of the mathematical preprocessing of spectral data is to reduce random and unwanted systematic variations to highlight the spectral features of interest. Supplemental Tables S1 to S5 contain a list of the mathematical preprocessing methods used by different researchers for predicting cheese composition. The most commonly used preprocessing methods for scatter correction (Rinnan et al., 2009) are multiplicative signal correction (Isaksson and Naes, 1988), standard normal variate (Barnes et al., 1993), and vector normalization. All of these methods reduce the physical variability and eliminate drift (Rinnan et al., 2009). Given that there are several types of normalization, such as area normalization, standard normal variate, and autoscaling, authors should specify which was used in each model. Merely mentioning that the data were preprocessed by normalization is not sufficient information. When scatter correction is combined with spectral derivatives, they should always be applied beforehand, with the exception of vector normalization (Rinnan et al., 2009).

Detrending is used to remove the effects of accumulating data sets so that only the absolute changes are shown, and derivatives are used to enhance spectral resolution and eliminate unimportant baseline signals from the samples (Savitzky and Golay, 1964). The first derivative removes the additive constant background (offset), and the second derivative removes offset and background drifts due to scattering (Barak, 1995). Preprocessing methods that operate on variable means, such as standardization, centering, and autoscaling, are also widely used (Bro and Smilde, 2003).

\section{Calibration Procedures}

The most popular multivariate techniques for obtaining prediction equations include partial least squares (PLS), multiple linear regressions (MLR), and some other forms of these 2 techniques (e.g., modified PLS and stepwise MLR; Karoui and Debaerdemaeker, 2007). More recently, other statistical procedures have been used, sometimes derived from those used in genomic calibrations (Ferragina et al., 2015). Stocco et al. (2019) used Bayesian regression models to build the calibration equations, whereas Lin et al. (2014) used back propagation artificial neural networks (BP-ANN) and least squares support vector machine (LS-SVM) for cheese.

It is important to evaluate and compare calibration procedures in relation to the mathematical pretreatment and the validation strategy adopted. In an original paper, Pierce and Wehling (1994) studied the effects of the interaction between type of data, mathematical pretreatment, and regression model on the calibration and cross-validation accuracy of moisture and fat prediction in Cheddar cheese. Type of data refers to whether absorbance was recorded in reflectance $(\mathrm{R})$ or transmittance $(\mathrm{T})$ mode (in both cases the absorbance values are calculated as the logarithmic transformation of the inverse of the data; $\log 1 / \mathrm{R}$ and $\log 1 / \mathrm{T})$. Aside from log-transformation of the inverse, other mathematical pretreatments they compared were as follows: none, first derivative, and second derivative. The regression models compared were as follows: MLR based on the absorbance of only 2, 3, or 4 individual wavelengths for each trait, and PLS based on 3 to 8 latent factors. The first result obtained was the $\mathrm{R}_{\mathrm{CAL}}^{2}$ of the 24 combinations tested $(2$ modes $\times 3$ pretreatments $\times 2$ models $\times 2$ traits), which were very high and similar to each other (0.83-0.99), except for the 4 combinations obtained in transmittance mode for fat $(0.72-0.80)$. Therefore, there is an evident interaction between the acquisition mode and the trait predicted (data not shown). The differences are larger and the interactions more evident for the accuracy of crossvalidation $\left(\mathrm{R}_{\text {VAL }}^{2}\right)$. This means that there is also an interaction between the accuracy parameter (calibration vs. validation) and the other factors. The interaction between trait and pretreatment or model is evident in Figure 8; the 12 combinations for predicting moisture that were tested were all high and differed little from each other (80-85\%), whereas those for predicting fat were much more variable. The use of MLR based on a few individual wavelengths was almost as accurate as PLS based on the entire spectrum using latent factors, with the exception of only a couple of combinations 
(model $\times$ mathematical pretreatment interaction), in which MLR or PLS was more accurate (Figure 8). In the case of fat, the prediction equations based on reflectance spectra were generally more accurate than those based on transmittance spectra, with a couple of exceptions (type of spectrum $\times$ mathematical pretreatment interaction). Finally, comparison of the different mathematical pretreatments (Figure 8) yielded different results according to the regression model and type of spectra (triple interaction). Oca et al. (2012) confirmed that calibration yields accuracy parameters that are different, sometimes dramatically different, from those from the validation data sets. The ranking of the different combinations of mathematical pretreatments is different for calibration and validation, and it is possible for the best combination for calibration to be the worst for validation. This is most likely due to the method of optimization process during calibration, such as cross-validation with the risk of overfitting, yielding worse results in validation. Nevertheless, more research is needed on this field. Similar results have been obtained for other foods of animal origin. Some of the other researchers also compared different calibration modeling techniques (Adams et al., 1999; McKenna, 2001; Lin et al., 2014), but their results are difficult to compare and interpret because they were obtained under very different conditions (e.g., different instruments, different cheeses, different nutrients analyzed, different mathematical pre-treatment used).

\section{Validation Strategies}

A proper validation procedure can yield very different accuracy statistics from those obtained by calibration procedures. It is worth pointing out that, in their comparison of different types of spectra (FTIR, NIR) and profiles (fatty acids, volatile organic compounds, and sensory descriptions) of milk and cheese for discriminating between different farming systems, Bergamaschi et al. (2020) found that calibration accuracy generally could be greatly inflated when based on a large number of spectral observations and profiles for each sample, whereas validation accuracy did not seem to be similarly affected by the number of predictors. Also, the $\mathrm{R}^{2}$ drops markedly from calibration to validation when there are large numbers of spectral observations or profiles and calibration accuracy is high. The inflation of calibration accuracy seems particularly evident with difficult-to-predict traits (Patel et al., 2020), hence for those traits whose predictions are mainly correlative in nature. The choice of chemometric model could also be important for difficult-to-predict traits, and here there is a preference for new procedures, sometimes developed for analyzing genomic date (e.g., Bayesian methods, machine learning methods), over the traditional PLS, which is still very useful for "easy" traits (Ferragina et al., 2015).

In general, cross-validation procedures have been often used to develop and validate calibration equations. Data may be split using random methods (McKenna, 2001; Da Costa Filho and Volery, 2005; Ottavian et al., 2012; Ma et al., 2019) or the Kennard-Stone algorithm (Botelho et al., 2013; Wiedemair et al., 2019). Leaveone-out cross-validation along with full cross-validation $(\mathrm{CV})$, block $\mathrm{CV}$, or contiguous $\mathrm{CV}$ have mostly been used. It should be borne in mind that there is a scarcity of studies testing prediction accuracy on a genuinely external validation set (i.e., containing cheese samples totally independent of those used for calibration such as different cheese origins or sampling periods). This means that the practical usefulness of the prediction equations obtained in this way in dairy industry conditions could be overstated, as affirmed also in the revised guidelines of the International Dairy Federation on applications of NIRS for the analysis of milk and milk products (Niermöller and Holroyd. 2019). However, when used for calibrations based on very large data sets (thousands of samples), cross-calibration could give a robust indication of the performance of the

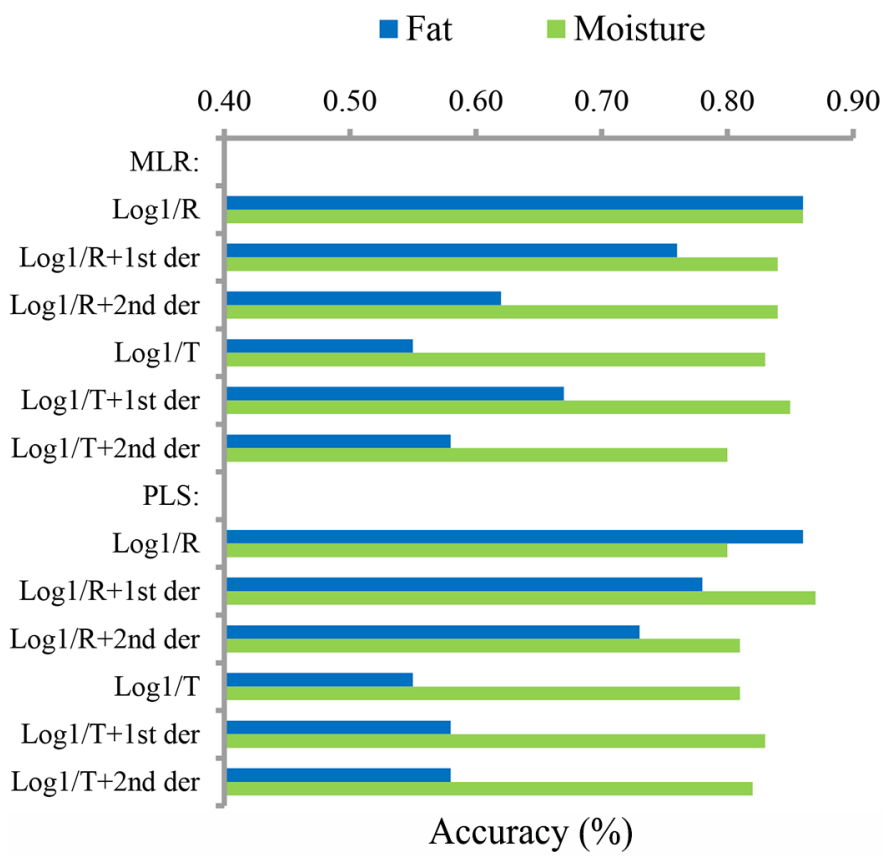

Figure 8. Effects of different statistical models and mathematical pretreatments of cheese spectra on the accuracy of cross-validation $\left(\mathrm{R}_{\mathrm{CV}}^{2}\right)$ of the prediction of lipids and protein in 52 Cheddar cheese samples (based on data presented in Pierce and Wehling, 1994). MLR $=$ multiple linear regression; PLS $=$ partial least squares regression; $\log 1 / \mathrm{R}=\log (1 /$ reflectance $) ; \log 1 / \mathrm{T}=\log (1 /$ transmittance $) ;$ der $=$ derivative. 
NIRS predictions. Further research is needed to define optimal validation strategies to apply the predictions of cheese composition in the field.

\section{CONCLUSIONS}

The main conclusions that we can draw from this review of published studies on the prediction of cheese composition by visible and infrared spectrometry are as follows. The Vis-NIR spectroscopy is a useful, rapid, inexpensive method for predicting the moisture, fat, and protein contents of cheese, and there is no need to collect, store, transport and process samples in the case of portable or handheld spectrometers. The prediction of other chemical components (e.g., salt, minerals, WSN) is less accurate and requires further research. It is important to balance the variability in the cheese samples used for calibrating the system to avoid the risk of obtaining prediction equations that are valid only for a very specific cheese type or the predictions being biased for a particular cheese type. Although there are large differences among the different spectrometers, they do not seem to depend too much on the instrument's spectrum extension. Several signals related to moisture, fat, and protein are present in different sections of the cheese spectrum, and thus predictions based on segments of the visible, IR-A, and IR-B regions could be almost as accurate as those based on a much wider spectrum. Mathematical pretreatments, chemometric models, and validation strategies interact with each other and should be evaluated jointly. The recently used chemometric models based on Bayesian or machine learning procedures outperform PLS in the case of difficult-to-predict traits. A genuinely external validation data set is needed to avoid overoptimistic results and for testing the accuracy of predictions in an industry environment.

\section{ACKNOWLEDGMENTS}

This study was supported by the University of Padova (Ricerca Scientifica fondi DOR-2018/2019, DOR1815378/18, and DOR1970230/19; Padua, Italy). Nageshvar Patel benefitted from financial support of the CARIPARO Foundation (Cassa di Risparmio di Padova e Rovigo; Padua, Italy). The authors have not stated any conflicts of interest.

\section{REFERENCES}

Abbas, O., and V. Baeten. 2018. Near infrared spectroscopy. Pages 80-87 in Spectroscopic methods in food analysis. 1st edition. A. S. Franca and L. M. L. Nollet, eds. CRC Press, Taylor and Francis Group.
Adamopoulos, K. G., A. M. Goula, and H. J. Petropakis. 2001. Quality control during processing of feta cheeses NIR application. J. Food Compos. Anal. 14:431-440. https://doi.org/10.1006/jfca .2000.0976.

Adams, M. J., K. Latham, N. W. Barnett, and A. J. Poynton. 1999. Calibration models for determining moisture and fat content of processed cheese using near-infrared spectrometry. J. Sci. Food Agric. 79:1232-1236. https://doi.org/10.1002/(SICI)1097 -0010(19990715)79:10<1232::AID-JSFA347>3.0.CO;2-R.

Barak, P. 1995. Smoothing and differentiation by an adaptive-degree polynomial filter. Anal. Chem. 67:2758-2762. https://doi.org/10 .1021/ac00113a006.

Barnes, R. J., M. S. Dhanoa, and S. J. Lister. 1993. Correction of the description of standard normal variate (SNV) and de-trend transformations in practical spectroscopy with applications in food and beverage analysis. J. Near Infrared Spectrosc. 1:185-186. https:// doi.org/10.1255/jnirs.21.

Bergamaschi, M., A. Cecchinato, F. Biasioli, F. Gasperi, B. Martin, and G. Bittante. 2016. From cow to cheese: Genetic parameters of the flavour fingerprint of cheese investigated by direct-injection mass spectrometry (PTR-ToF-MS). Genet. Sel. Evol. 48:89. https: //doi.org/10.1186/s12711-016-0263-4.

Bergamaschi, M., C. Cipolat-Gotet, A. Cecchinato, S. Schiavon, and G. Bittante. 2020. Chemometric authentication of farming systems of origin of food (milk and ripened cheese) using infrared spectra, fatty acid profiles, flavor fingerprints, and sensory descriptions. Food Chem. 305:125480. https://doi.org/10.1016/j.foodchem.2019 .125480 .

Biggs, D. A. 1979. Applications of infrared instrumentation in cheese analysis. Pages 409-414 in Proc. first Bienn. Marschall Int. Cheese Conf. Marschall Dairy Ingred. Div. Miles Lab, Inc.

Bittante, G., and A. Cecchinato. 2013. Genetic analysis of the Fouriertransform infrared spectra of bovine milk with emphasis on individual wavelengths related to specific chemical bonds. J. Dairy Sci. 96:5991-6006. https://doi.org/10.3168/jds.2013-6583.

Bittante, G., C. Cipolat-Gotet, and A. Cecchinato. 2013. Genetic parameters of different measures of cheese yield and milk nutrient recovery from an individual model cheese-manufacturing process. J. Dairy Sci. 96:7966-7979. https://doi.org/10.3168/jds.2012-6517.

Bittante, G., A. Ferragina, C. Cipolat-Gotet, and A. Cecchinato. 2014 Comparison between genetic parameters of cheese yield and nutrient recovery or whey loss traits measured from individual model cheese-making methods or predicted from unprocessed bovine milk samples using Fourier-transform infrared spectroscopy. J. Dairy Sci. 97:6560-6572. https://doi.org/10.3168/jds.2014-8309.

Blazquez, C., G. Downey, C. O'Donnell, D. O'Callaghan, and V. Howard. 2004. Prediction of moisture, fat and inorganic salts in processed cheese by near infrared reflectance spectroscopy and multivariate data analysis. J. Near Infrared Spectrosc. 12:149-157. https://doi.org/10.1255/jnirs.420.

Botelho, B. G., B. A. P. Mendes, and M. M. Sena. 2013. Development and analytical validation of robust near-infrared multivariate calibration models for the quality inspection control of mozzarella cheese. Food Anal. Methods 6:881-891. https://doi.org/10.1007/ s12161-012-9498-z.

Bro, R., and A. K. Smilde. 2003. Centering and scaling in component analysis. J. Chemometr. 17:16-33. https://doi.org/10.1002/cem .773 .

Cattaneo, T. M. P., and S. Barzaghi. 2009. Outer product analysis applied to near infrared and mid infrared spectra to study a Spanish protected denomination of origin cheese. J. Near Infrared Spectrosc. 17:135-140. https://doi.org/10.1255/jnirs.832.

Cecchinato, A., A. Albera, C. Cipolat-Gotet, A. Ferragina, and G. Bittante. 2015. Genetic parameters of cheese yield and curd nutrient recovery or whey loss traits predicted using Fourier-transform infrared spectroscopy of samples collected during milk recording on Holstein, Brown Swiss, and Simmental dairy cows. J. Dairy Sci. 98:4914-4927. https://doi.org/10.3168/jds.2014-8599.

Cecchinato, A., H. Toledo-Alvarado, S. Pegolo, A. Rossoni, E. Santus, C. Maltecca, G. Bittante, and F. Tiezzi. 2020. Integration of wet- 
lab measures, milk infrared spectra, and genomics to improve difficult-to-measure traits in dairy cattle populations. Front. Genet. 11:563393. https://doi.org/10.3389/fgene.2020.563393.

CIE (International Commission on Illumination). 2004. Colorimetry. 3rd ed. CIE 015. CIE.

Cozzi, G., J. Ferlito, G. Pasini, B. Contiero, and F. Gottardo. 2009. Application of near-infrared spectroscopy as an alternative to chemical and color analysis to discriminate the production chains of Asiago d'Allevo cheese. J. Agric. Food Chem. 57:11449-11454.

Čurda, L., and O. Kukačková. 2004. NIR spectroscopy: A useful tool for rapid monitoring of processed cheeses manufacture. J. Food Eng. 61:557-560. https://doi.org/10.1016/S0260-8774(03)00215-2.

da Costa Filho, P. A., and P. Volery. 2005. Broad-based versus specific NIRS calibration: Determination of total solids in fresh cheese. Anal. Chim. Acta 544:82-88. https://doi.org/10.1016/j.aca.2005 .03 .022 .

De Maesschalck, R., D. Jouan-Rimbaud, and D. L. Massart. 2000. The Mahalanobis distance. Chemom. Intell. Lab. Syst. 5:1-18.

De Marchi, M., M. Penasa, A. Zidi, and C. L. Manuelian. 2018. Invited review: Use of infrared technologies for the assessment of dairy products - Applications and perspectives. J. Dairy Sci. 101:1058910604. https://doi.org/10.3168/jds.2018-15202.

Eskildsen, C. E., K. W. Sanden, S. G. Wubshet, P. V. Andersen, J. Øyaas, and J. P. Wold. 2019. Estimating dry matter and fat content in blocks of Swiss cheese during production using on-line near infrared spectroscopy. J. Near Infrared Spectrosc. 27:293-301. https://doi.org/10.1177/0967033519855436.

Eurostat. 2020. Milk and milk product statistics: Statistics explained. Accessed Jul. 28, 2021. https://ec.europa.eu/eurostat/statistics -explained/index.php?title=Milk_and_milk_product_statistics

Fernández Pierna, J. A., P. Vermeulen, B. Lecler, V. Baeten, and P. Dardenne. 2010. Calibration transfer from dispersive instruments to handled spectrometers. Appl. Spectrosc. 64:644-648. https:// doi.org/10.1366/000370210791414353.

Ferragina, A., G. de los Campos, A. I. Vazquez, A. Cecchinato, and G. Bittante. 2015. Bayesian regression models outperform partial least squares methods for predicting milk components and technological properties using infrared spectral data. J. Dairy Sci. 98:8133-8151. https://doi.org/10.3168/jds.2014-9143.

Frank, J. F., and G. S. Birth. 1982. Application of near infrared reflectance spectroscopy to cheese analysis. J. Dairy Sci. 65:1110-1116. https://doi.org/10.3168/jds.S0022-0302(82)82319-9.

Giangiacomo, R., and R. Nzabonimpa. 1994. Approach to near infrared spectroscopy. Bull. Int. Dairy Fed. 298:37-42.

González-Martín, I., C. González-Pérez, J. M. Hernández-Hierro, and J. M. González-Cabrera. 2008. Use of NIRS technology with a remote reflectance fibre-optic probe for predicting major components in cheese. Talanta 75:351-355. https://doi.org/10.1016/j talanta.2007.11.028.

González-Martín, M. I., P. Severiano-Pérez, I. Revilla, A. M. VivarQuintana, J. M. Hernández-Hierro, C. González-Pérez, and I. A. Lobos-Ortega. 2011. Prediction of sensory attributes of cheese by near-infrared spectroscopy. Food Chem. 127:256-263. https://doi .org/10.1016/j.foodchem.2010.12.105.

Isaksson, T., and T. Naes. 1988. The effect of multiplicative scatter correction (MSC) and linearity improvement in NIR spectroscopy. Appl. Spectrosc. 42:1273-1284. https://doi.org/10.1366/ 0003702884429869.

ISO. 2006. Milk products - Guidelines for the application of near infrared spectrometry, ISO standard number 21543:2006. IDF standard number 201:2006. ISO.

ISO. 2020. Milk and Milk products - Guidelines for the application of near infrared spectrometry, updated guideline. ISO standard number 21543:2020, IDF standard number 201:2020. ISO.

Karoui, R., and J. Debaerdemaeker. 2007. A review of the analytical methods coupled with hemometric tools for the determination of the quality and identity of dairy products. Food Chem. 102:621640. https://doi.org/10.1016/j.foodchem.2006.05.042.

Karoui, R., E. Dufour, L. Pillonel, E. Schaller, D. Picque, T. Cattenoz, and J.-O. Bosset. 2005. The potential of combined infrared and fluorescence spectroscopies as a method of determination of the geographic origin of Emmental cheeses. Int. Dairy J. 15:287-298. https://doi.org/10.1016/j.idairyj.2004.07.005.

Karoui, R., A. M. Mouazen, É. Dufour, L. Pillonel, E. Schaller, D. Picque, J. De Baerdemaeker, and J.-O. Bosset. 2006a. A comparison and joint use of NIR and MIR spectroscopic methods for the determination of some parameters in European Emmental cheese. Eur. Food Res. Technol. 223:44-50. https://doi.org/10.1007/ s00217-005-0110-2.

Karoui, R., A. M. Mouazen, É. Dufour, R. Schoonheydt, and J. De Baerdemaeker. 2006b. A comparison and joint use of VIS-NIR and MIR spectroscopic methods for the determination of some chemical parameters in soft cheeses at external and central zones: A preliminary study. Eur. Food Res. Technol. 223:363-371. https:// doi.org/10.1007/s00217-005-0213-9.

Karoui, R., A. M. Mouazen, H. Ramon, R. Schoonheydt, and J. D. Baerdemaeker. 2006c. Feasibility study of discriminating the manufacturing process and sampling zone in ripened soft cheeses using attenuated total reflectance MIR and fiber optic diffuse reflectance VIS-NIR spectroscopy. Food Res. Int. 39:588-597. https://doi.org/ 10.1016/j.foodres.2005.12.002.

Kraggerud, H., T. Næs, and A. R. Abrahamsen. 2014. Prediction of sensory quality of cheese during ripening from chemical and spectroscopy measurements. Int. Dairy J. 34:6-18. https://doi.org/10 .1016/j.idairyj.2013.07.008.

Lee, S. J., I. J. Jeon, and L. H. Harbers. 1997. Near-infrared reflectance spectroscopy for rapid analysis of curds during cheddar cheese making. J. Food Sci. 62:53-56. https://doi.org/10.1111/j .1365-2621.1997.tb04367.x.

Lei, T., and D. W. Sun. 2019. Developments of nondestructive techniques for evaluating quality attributes of cheeses: A review. Trends Food Sci. Technol. 88:527-542. https://doi.org/10.1016/j .tifs.2019.04.013.

Lénárt, J., T. Szigedi, M. Dernovics, and M. Fodor. 2012. Application of FT-NIR spectroscopy on the determination of the fat and protein contents of lyophilized cheeses. Acta Aliment. 41:351-362. https://doi.org/10.1556/AAlim.41.2012.3.7.

Lin, P., Y. M. Chen, Y. He, G. W. Hu, X. L. Fu, and C. L. Gu. 2014. Study on nonlinear multivariate methods combined with the visible near-infrared spectroscopy (vis/nirs) technique for detecting the protein content of cheese. Food Biopro. Tech. 7:3359-3369. https://doi.org/10.1007/s11947-014-1341-7.

Lucas, A., D. Andueza, E. Rock, and B. Martin. 2008. Prediction of dry matter, fat, $\mathrm{pH}$, vitamins, minerals, carotenoids, total antioxidant capacity, and color in fresh and freeze-dried cheeses by visible-near-infrared reflectance spectroscopy. J. Agric. Food Chem. 56:6801-6808. https://doi.org/10.1021/jf800615a.

Ma, Y. B., K. S. Babu, and J. K. Amamcharla. 2019. Prediction of total protein and intact casein in cheddar cheese using a low-cost handheld short-wave near-infrared spectrometer. Lebensm. Wiss. Technol. 109:319-326. https://doi.org/10.1016/j.lwt.2019.04.039.

Madalozzo, E. S., E. Sauer, and N. Nagata. 2015. Determination of fat, protein and moisture in ricotta cheese by near infrared spectroscopy and multivariate calibration. J. Food Sci. Technol. 52:16491655. https://doi.org/10.1007/s13197-013-1147-z.

Margolies, B. J., and D. M. Barbano. 2018. Determination of fat, protein, moisture, and salt content of Cheddar cheese using midinfrared transmittance spectroscopy. J. Dairy Sci. 101:924-933. https://doi.org/10.3168/jds.2017-13431

Martín-del-Campo, S. T., D. Picque, R. Cosío-Ramírez, and G. Corrieu. 2007. Evaluation of chemical parameters in soft mold-ripened cheese during ripening by mid-infrared spectroscopy. J. Dairy Sci. 90:3018-3027. https://doi.org/10.3168/jds.2006-656.

Mazerolles, G., G. Duboz, and S. Hugot. 2000. Détermination des taux d'humidité et de matière grasse de fromages de type pâte pressée par spectroscopie proche infrarouge en mode transmission. Lait 80:371-379. https://doi.org/10.1051/lait:2000132.

McKenna, D. 2001. Measuring moisture in cheese by near infrared absorption spectroscopy. J. AOAC Int. 84:623-628. https://doi.org/ 10.1093/jaoac/84.2.623.

McQueen, D. H., R. Wilson, A. Kinnunen, and E. P. Jensen. 1995. Comparison of two infrared spectroscopic methods for cheese 
analysis. Talanta 42:2007-2015. https://doi.org/10.1016/0039 -9140(95)01685-6.

Niemöller, A., and S. Holroyd. 2019. Applications of near infrared spectrometry for the analysis of milk and milk products. Bull. Int. Dairy Fed. 497/2019:1-19

Núñez-Sánchez, N., A. Garrido-Varo, J. M. Serradilla, and J. L. Ares. 1999. Reflectance versus interactance reflectance near infrared analysis of homogenised and intact ewe cheese. Pages 135-138 in Proc. 9th International Conference on Near-Infrared Spectroscopy, Verona, Italy.

Oca, M. L., M. C. Ortiz, L. A. Sarabia, A. E. Gredilla, and D. Delgado. 2012. Prediction of Zamorano cheese quality by near-infrared spectroscopy assessing false non-compliance and false compliance at minimum permitted limits stated by designation of origin regulations. Talanta 99:558-565. https://doi.org/10.1016/j.talanta .2012 .06 .035

Ottavian, M., P. Facco, M. Barolo, P. Berzaghi, S. Segato, E. Novelli, and S. Balzan. 2012. Near-infrared spectroscopy to assist authentication and labeling of Asiago d'allevo cheese. J. Food Eng. 113:289-298. https://doi.org/10.1016/j.jfoodeng. 2012.05.037.

Panikuttira, B., N. O'Shea, J. T. Tobin, B. K. Tiwari, and C. P. O'Donnell. 2018. Process analytical technology for cheese manufacture. Int. J. Food Sci. Technol. 53:1803-1815. https://doi.org/ 10.1111 /ijfs. 13806 .

Papetti, P., C. Costa, F. Antonucci, S. Figorilli, S. Solaini, and P. Menesatti. 2012. A RFID web-based infotracing system for the artisanal Italian cheese quality traceability. Food Control 27:234241. https://doi.org/10.1016/j.foodcont.2012.03.025.

Patel, N., H. Toledo-Alvarado, A. Cecchinato, and G. Bittante. 2020. Predicting the content of 20 minerals in beef by different portable near-infrared (NIR) spectrometers. Foods 9:1389. https://doi.org/ 10.3390/foods9101389

Pegolo, S., M. Bergamaschi, F. Gasperi, F. Biasioli, A. Cecchinato, and G. Bittante. 2018. Integrated PTR-ToF-MS, GWAS and biological pathway analyses reveal the contribution of cow's genome to cheese volatilome. Sci. Rep. 8:17002. https://doi.org/10.1038/ s41598-018-35323-5.

Pi, F., H. Shinzawa, Y. Ozaki, and D. Han. 2009. Non-destructive determination of components in processed cheese slice wrapped with a polyethylene film using near-infrared spectroscopy and chemometrics. Int. Dairy J. 19:624-629. https://doi.org/10.1016/ j.idairyj.2009.05.002.

Pierce, M. M., and R. L. Wehling. 1994. Comparison of sample handling and data treatment methods for determining moisture and fat in cheddar cheese by near-infrared spectroscopy. J. Agric. Food Chem. 42:2830-2835. https://doi.org/10.1021/jf00048a033.

Polesello, A., R. Giangiacomo, and G. G. Dull. 1983. Application of near infrared spectrophotometry to the nondestructive analysis of foods: A review of experimental results. CRC Crit. Rev. Food Sci. Nutr. 18:203-230. https://doi.org/10.1080/10408398309527363.

Pu, Y.-Y., C. O'Donnell, J. T. Tobin, and N. O'Shea. 2020. Review of near-infrared spectroscopy as a process analytical technology for real-time product monitoring in dairy processing. Int. Dairy J. 103:104623. https://doi.org/10.1016/j.idairyj.2019.104623.

Rinnan, A., F. van den Berg, and S. B. Engelsen. 2009. Review of the most common pre-processing techniques for near-infrared spectra.
Trends Analyt. Chem. 28:1201-1222. https://doi.org/10.1016/j trac.2009.07.007.

Rodriguez-Otero, J. L., M. Hermida, and A. Cepeda. 1995. Determination of fat, protein, and total solids in cheese by near-infrared reflectance spectroscopy. J. AOAC Int. 78:802-806. https://doi.org/ $10.1093 / \mathrm{jaoac} / 78.3 .802$.

Savitzky, A., and M. Golay. 1964. Smoothing and differentiation of data by simplified least squares procedures. Anal. Chem. 36:16271639. https://doi.org/10.1021/ac60214a047.

Savoia, S., A. Albera, A. Brugiapaglia, L. Di Stasio, A. Ferragina, A. Cecchinato, and G. Bittante. 2020. Prediction of meat quality traits in the abattoir using portable and hand-held near-infrared spectrometers. Meat Sci. 161:108017. https://doi.org/10.1016/j meatsci.2019.108017.

Sena, M. M., M. R. M. Almeida, J. W. B. Braga, and R. J. Poppi. 2018. Multivariate Statistical Analysis and Chemometrics. Pages 275-308 in Spectroscopic Methods in Food Analysis. 1st ed. A. S. Franca and L. M. L. Nollet, ed. CRC Press/Taylor and Francis Group.

Stocco, G., C. Cipolat-Gotet, A. Ferragina, P. Berzaghi, and G. Bittante. 2019. Accuracy and biases in predicting the chemical and physical traits of many types of cheeses using different visible and near-infrared spectroscopic techniques and spectrum intervals. J. Dairy Sci. 102:9622-9638. https://doi.org/10.3168/jds.2019-16770.

Stocco, G., C. Cipolat-Gotet, V. Gasparotto, A. Cecchinato, and G. Bittante. 2018. Breed of cow and herd productivity affect milk nutrient recovery in curd, and cheese yield, efficiency and daily production. Animal 12:434-444. https://doi.org/10.1017/ S1751731117001471.

Teixeira dos Santos, C. A., M. Lopo, R. N. M. J. Páscoa, and J. A. Lopes. 2013. A review on the applications of portable near-infrared spectrometers in the agro-food industry. Appl. Spectrosc. 67:12151233. https://doi.org/10.1366/13-07228.

USDA-FAS (Foreign Agricultural Service). 2021. Dairy: World markets and trade. World Agricultural Outlook Board/USDA. Accessed Nov. 4, 2021. https://apps.fas.usda.gov/psdonline/circulars/dairy .pdf.

Viscarra Rossel, R. A., H. J. Taylor, and A. B. McBratney. 2007. Multivariate calibration of hyperspectral $\gamma$-ray energy spectra for proximal soil sensing. Eur. J. Soil Sci. 58:343-353. https://doi.org/ 10.1111/j.1365-2389.2006.00859.x.

Wiedemair, V., D. Langore, R. Garsleitner, K. Dillinger, and C. Huck. 2019. Investigations into the performance of a novel pocket-sized near-infrared spectrometer for cheese analysis. Molecules 24:428. https://doi.org/10.3390/molecules24030428.

Williams, P., P. Dardenne, and P. Flinn. 2017. Tutorial: Items to be included in a report on a near infrared spectroscopy project. J. Near Infrared Spectrosc. 25:85-90. https://doi.org/10.1177/ 0967033517702395.

Wittrup, C., and L. Nørgaard. 1998. Rapid near infrared spectroscopic screening of chemical parameters in semi-hard cheese using chemometrics. J. Dairy Sci. 81:1803-1809. https://doi.org/10.3168/jds .S0022-0302(98)75749-2. 